NBER WORKING PAPER SERIES

\title{
SPECULATIVE GROWTH
}

\author{
Ricardo J. Caballero \\ Mohamad L. Hammour \\ Working Paper 9381 \\ http://www.nber.org/papers/w9381
}

\author{
NATIONAL BUREAU OF ECONOMIC RESEARCH \\ 1050 Massachusetts Avenue \\ Cambridge, MA 02138 \\ December 2002
}

We are grateful to Björn Brügmann for outstanding research assistance and to the European Central Bank Research Department and the International Institute for Economic Studies for their hospitality. We thank Franklin Allen, Marios Angeletos, Gadi Barlevy, Olivier Blanchard, Thomas Chaney, Peter Diamond, Thomas Philippon, Frank Portier, Pietro Riechlin, Jean Tirole, Jaume Ventura and seminar participants at CORE, DELTA, ESSIM, IIES, MIT, the NBER EFG meetings, Northwestern, Toulouse, and Wharton for useful comments. Caballero thanks the NSF for financial support. First draft: May 2001. The views expressed herein are those of the authors and not necessarily those of the National Bureau of Economic Research.

(C) 2002 by Ricardo J. Caballero and Mohamad L. Hammour. All rights reserved. Short sections of text, not to exceed two paragraphs, may be quoted without explicit permission provided that full credit, including (C) notice, is given to the source. 
Speculative Growth

Ricardo J. Caballero and Mohamad L. Hammour

NBER Working Paper No. 9381

December 2002

JEL No. D0, D9, E2, E3, G1, H3

\begin{abstract}
$\underline{\text { ABSTRACT }}$
We propose a framework for understanding recurrent historical episodes of vigorous economic expansion accompanied by extreme asset valuations, as exhibited by Japan in the 1980 's and the U.S. in the 1990's. We interpret this phenomenon as a high-valuation equilibrium with a low effective cost of capital based on optimism about the future availability of funds for investment. The key to the sustainability of such equilibrium is feedback from increased growth to an increase in the supply of funding. We show that such feedback arises naturally when the expansion is concentrated in a "new economy" sector and when it is supported by sustained financial surpluses-both of which would constitute an integral part, as cause and consequence, of a "speculative growth"equilibrium. The high-valuation equilibrium we analyze may take the form of a stock market bubble. In contrast to classic bubbles on non-productive assets, the bubbles in our model encourage real investments, boost long run savings, and may appear in dynamically efficient economies.
\end{abstract}

Ricardo J. Caballero

Department of Economics

MIT

$\mathrm{E} 52,252$

Cambridge, MA 02142

and NBER

caball@mit.edu
Mohamad Hammour

Delta-ens

48 Boulevard Jourdan

Paris 75014

France

hammour.delta.ens.fr 


\section{Introduction}

The last two decades have witnessed stark "speculative growth" episodes of extreme stock market valuations accompanied by brisk economic growth. Most notable was the experience of Japan in the 1980s and the United States in the 1990s. Figure 1a illustrates the sharp rise in the Nikkei in the 1980s, followed by the two-year slide of 1990-1992; and the sharp rise in the NASDAQ in the 1990s, followed by the collapse of 2000-2001. The extremes reached by valuations shown in figure $1 \mathrm{~b}$, and their collapse in the absence of obvious changes in fundamentals, are suggestive of a stock market bubble. Figures 1c and 1d illustrate the growth and investment boom-and-bust that accompanied the market's gyrations.

1.a: The Nikkei 225 and the NASDAQ

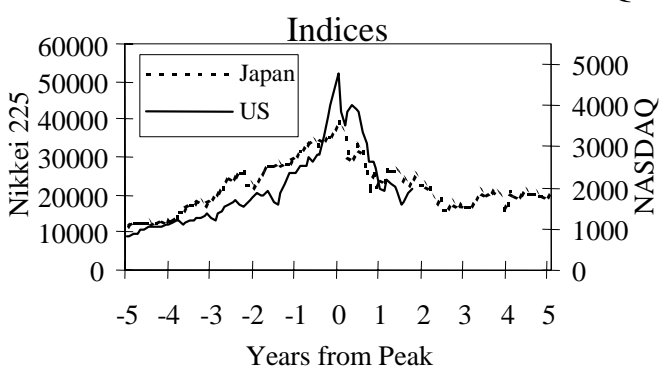

1.c: Real GDP Growth (\%)

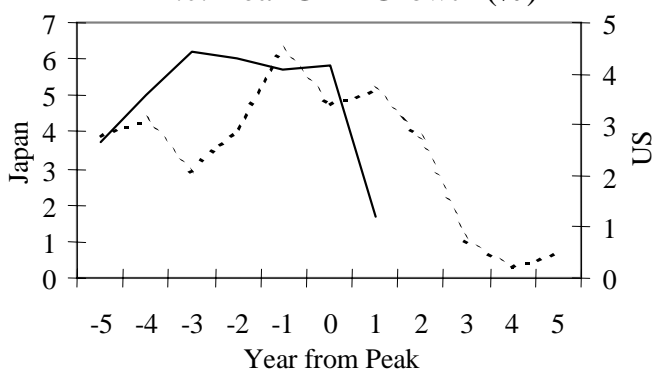

1.b: Price/Earnings Ratio

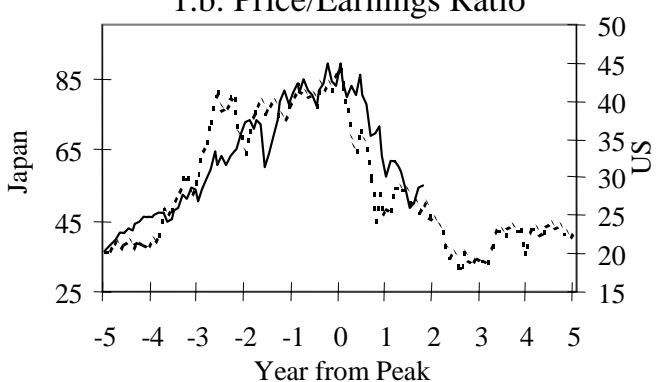

1.d: Investment/GDP (\%)

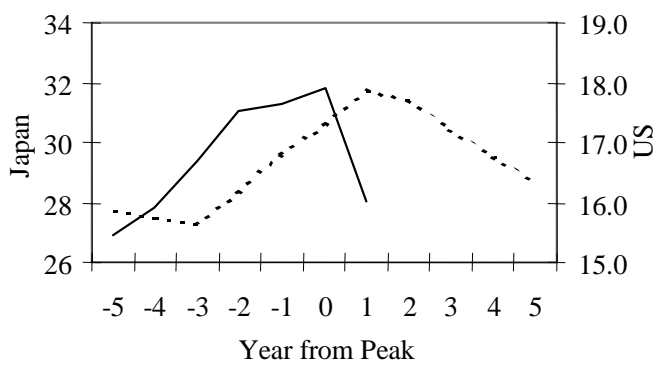

Note: Panel b: numerator is real (inflation-adjusted) Datastream Total Market Index; denominator is moving average over preceding ten years of real earnings corresponding to the index.

Sources: Panel a: Nasdaq Composite Index from The Nasdaq Stock Market, Inc; Nikkei 225 from Datastream. Panel b: Datastream Total Market Index for US and Japan; CPIs from OECD Main Economic Indicators (all items). Panel c: Bureau of Economic Analysis (BEA), NIPA Table 1.2; Economic and Social Research Insitute (ESRI). Panel d: BEA, NIPA Table 1.1; Annual report on national accounts (CD-ROM) 1998

Figure 1: Speculative Growth Episodes

The nature and policy dilemmas of speculative expansions have attracted much attention (e.g., International Monetary Fund 2000, Shiller 2000, Cecchetti et al. 2000), but our formal understanding of the macroeconomic mechanisms that underlie the relation between stock market speculation and real economic activity remains quite limited. In fact, the clas- 
sic literature on bubbles in general equilibrium bears little relation to speculative growth episodes. In this literature, bubbles - understood as asset prices that deviate from fundamental values - can only appear in a "dynamically inefficient" economy, that is one whose structure is conducive to the over-accumulation of capital. Their emergence helps to absorb saving away from investment and to alleviate the over-accumulation problem. However, the notion that the emergence of a bubble would crowd out investment, while its bursting would increase investment, is contrary to the patterns depicted in figure 1. Moreover, empirical testing of "dynamic inefficiency" has been negative. Abel et al. (1989) tested an implication of dynamic inefficiency, whether the aggregate market for assets acts as a long-term "cash sink" for investors, but found no evidence of it in OECD economies.

This paper proposes an alternative framework for understanding speculative expansions that is better able to address the facts. Our interpretation of this phenomenon rests on two premises: (i) the rise in market valuations in speculative growth episodes results from a low effective long-term cost of capital; and (ii) the boom in investment and growth during such episodes is a response to increased asset prices along the standard $q$-theory line. The central question that arises under this interpretation is: How are expectations of a low long-term cost of capital consistent with the high demand for savings needed to fund a high-investment equilibrium? A key component of our equilibrium account is a growthsaving feedback by which the future supply of savings increases as a result of the conditions created by a speculative expansion, and ends up lowering the effective cost of capital.

The kind of stock market bubbles that can arise in the presence of growth-saving feedback have very different implications from standard bubbles. First, rather than crowding out capital accumulation, they naturally encourage investment and growth. Conversely, their bursting leads to an investment slump as the economy rids itself of what appears $e x$ post as widespread overcapacity. Second, because they induce greater saving, such bubbles are expected to reduce the long-run cost of capital; this, one can show, allows them to arise in a dynamically efficient context. Finally, such bubbles and the resulting speculative expansions are manifestations of a more general class of low cost-of-capital equilibria that are the result of the feedback from growth to saving. Such equilibria are qualitatively similar to bubbly equilibria, in that they exhibit high asset valuations and can involve a collapse in asset prices in the absence of any news. However, these equilibria may or may not incorporate a bubble in asset markets, depending on how extreme valuation levels are. In other words, although consistent with market participants' perception of a stock market bubble, our account of speculative expansions does not hinge on ascertaining the presence 
of a bubble.

In the particular case of the U.S. in the 1990s, we argue, at least two factors created the conditions for a speculative growth episode: the emerging information technology sector and conservative fiscal policy. Both factors created favorable conditions for growth-saving feedback and for the possibility of a speculative equilibrium characterized by extreme stock market valuations and a potential crash.

How does the information technology sector generate feedback from growth to saving? This is an emerging sector of the economy, subject to a lesser degree of diminishing returns than more mature sectors. As the economy expands, such a "new economy" sector naturally will expand proportionally more than the rest of the economy and will have a greater ability to generate income for saving. Moreover, in an endogenous growth version of this model, we show that a bubble not only might be necessary for productivity growth to accelerate, but that the resulting expansion in productivity, income, and saving also might be critical to creating the growth-saving feedback necessary to support the bubble. Thus, a fundamental expansion in productivity and stock market speculation are not necessarily competing explanations. A technological revolution might form an integral part — both as cause and consequence - of a speculative growth equilibrium.

What about fiscal policy? We note that a significant share of increased saving in the recent U.S. speculative expansion is attributable to the public sector. To the extent that pro-cyclical government revenues increase public saving, they reinforce the feedback from growth to saving. In the short run, fiscal surpluses can arise as a consequence of the stock market boom and can facilitate the initial rise in investment. More importantly, fiscal surpluses can play a central role in making the speculative equilibrium feasible by providing the funding necessary to sustain high investment in the long run. This consideration has a particularly stark implication for fiscal policy during a speculative growth episode. The possibility of using the fiscal surpluses that result from such expansions to cut taxes and raise spending might be illusory, as these surpluses might be necessary to sustain the speculative growth equilibrium that generated them.

The speculative growth episodes to which our theory relates are a recurrent phenomenon. Earlier episodes of vigorous economic expansion under speculative asset valuations have been documented by economic historians. In the case of the U.S., this phenomenon also can be observed in the expansions of the turn of the 20th century, the 1920s, and the 1960s (see, e.g., Shiller 2000). Equally important, our theory can be brought to bear on sustained low cost-of-capital equilibria, such as the prolonged expansions exhibited in a number of East 
Asian economies in the post-war period. In fact, the key feedback from growth to saving in these economies has been documented. Examining the aggregate relationship between income growth and saving in a cross-country panel of 64 countries over the period 19581987, Caroll and Weil (1994) find that growth Granger causes saving with a positive sign, but that saving does not Granger cause growth. The pattern of an acceleration in growth followed by strong increases in saving rates is particularly clear in the high-growth, highsaving East Asian economies of Japan, South Korea, Singapore, and Hong Kong. Gavin et al. (1997) elaborate on this evidence and show that the estimated impact of growth on saving is not only statistically significant but also very large in economic terms.

\section{Relation to the literature}

In its economic theme, this paper is part of a long tradition of studies of speculative growth episodes (e.g., Kindleberger 1989). In terms of the recent U.S. experience, this literature is divided between those who see a case of speculative behavior (e.g., Shiller 2000), and those who, based on the significant acceleration in underlying U.S. productivity growth, conclude that the expansion was driven by a technological revolution that affected real fundamentals (e.g., Greenwood and Jovanovic, 1999; Hobijn and Jovanovic, 2000). From this perspective, our contribution is to provide a unified perspective under which these two views need not be mutually exclusive. On the contrary, an expansion of technological opportunities and stock market speculation may be inseparable complements. ${ }^{1}$

On the methodological side, our paper belongs to the literature on bubbles in general equilibrium. As we mentioned earlier, the classic theory of bubbles in general equilibrium (see Tirole 1985) is not designed well for addressing speculative growth episodes. It implies that a bubble crowds out investment and only can arise in a dynamically inefficient economy. Neither of these elements is observed during these episodes. From this perspective, the main distinctive feature of our framework is the centrality of the growth-saving mechanism. The latter overturns standard conclusions by breaking the crowding-out mechanism of equilibrium bubbles. Moreover, bubbly equilibria in our setting are a particular case of low cost-of-capital equilibria, that exhibit the same qualitative features but do not hinge

\footnotetext{
${ }^{1}$ The standard "technological revolution" interpretation faces a double challenge. First, in order to explain the collapse of the market, it must assume a reversal of technological market expectations that finds no counterpart in the commentary of market participants and their broad consensus that a bubble had burst. Second, this interpretation does not match well with the decline during the expansion of long-term interest rates and other measures of the cost of capital. The interpretation we offer in this paper shows that these two aspects of the US expansion are not only compatible with a technological revolution, but might be essential factors in its emergence.
} 
on ascertaining the existence of a bubble.

More recently, several papers have demonstrated that, in the presence of externalities that create a wedge between private and social returns on investment, bubbles can arise even if the bubbleless economy is dynamically efficient (e.g., Saint-Paul, 1992; Grossman and Yanagawa, 1993; King and Ferguson, 1993). That is because dynamic efficiency requires that the social rate of return exceed the rate of growth of the economy; the possibility of a bubble instead requires that the private rate of return be below the rate of growth. These two conditions are simultaneously feasible in the presence of a wedge between private and social returns. However, the cash-flow test for bubbles developed by Abel et al. (1989) still applies in the case of externalities because it concerns private returns, and rejects the possibility of standard bubbles. In contrast, our mechanism does not depend on a wedge between private and social returns, and a bubble can arise even if the speculative path starts with a private return that exceeds the rate of growth of the economy. In particular, our mechanism passes Abel et al.'s test.

In standard models, bubbles reduce investment and growth by crowding out investment. Olivier (2000) contributed to this literature by developing a model of bubbles on firm creation which, like ours, leads to more rather than less investment. ${ }^{2}$ However, because he does not incorporate a growth-saving feedback, bubbles in his model raise rather than lower the long-term cost of capital. This makes it challenging for a bubble to account simultaneously for high stock market valuations and high investment. In fact, for the bubble in Olivier's model to be price-increasing (see Weil 1990) - i.e., for the negative effect on asset prices caused by the rise in the interest rate to be dominated by the positive effect of the bubble - a large degree of ex-ante dynamic inefficiency is required.

The rest of this paper is organized as follows. In section 2, we present a prototypical model of speculative growth. Our analysis is based on the Diamond (1965) overlappinggenerations model, to which we add adjustment costs and a special assumption about the saving function. Adjustment costs allow us to characterize stock market booms and their key role in facilitating the transition from low- to high-investment equilibria. Our special saving function generically captures the growth-saving feedback that is central to the existence of a high-valuation equilibrium. Section 3 presents a specific instance of the generic mechanisms of section 2 in a model of the "new economy." In section 4, we extend our analysis to encompass fiscal surpluses and current account deficits as short- and longrun funding mechanisms. Section 5 concludes and is followed by an appendix that presents

\footnotetext{
${ }^{2}$ See also Cozzi (1998) for a related model applied to education decisions (culture as a bubble).
} 
the proofs of the main propositions.

\section{Speculative Growth: The Mechanics}

In this section we present a prototypical model of speculative growth. Our analysis is based on the Diamond (1965) overlapping-generations model, to which we add adjustment costs to capital and a special assumption about the saving function. Adjustment costs are important in any model in which changes in stock market valuations are central; otherwise the price of capital would be constant. The special assumption about the saving function is intended to capture the growth-saving feedback that is central to our interpretation of speculative expansions. This section introduces the feedback generically through the functional form of the saving function. The next two sections pay closer attention to specific macroeconomic mechanisms - the "new economy" and fiscal conservatism - that can create feedback from growth to saving and help explain recent speculative growth episodes.

\subsection{Model Setup}

Consider a standard Diamond (1965) overlapping-generations structure with no population growth and a unit mass of young and old agents who coexist at any date $t$. Each generation is born with a unit of labor, $L_{t}=\bar{L} \equiv 1$, to be used when young, for which it receives a total wage $W_{t}$ determined in a competitive, full-employment labor market. The economy's single consumption good is used as a numéraire.

Technology. Consumption goods are produced with capital, $K_{t}$, and labor, $L_{t}$. The production function at any time $t$ is determined by the level of technology, $A_{t}$, which grows at an exogenous rate $\gamma$ :

$$
A_{t+1}=(1+\gamma) A_{t}
$$

Production is given by a constant returns technology:

$$
Y_{t}=F\left(K_{t}, A_{t} L_{t}\right)=A_{t} L f\left(k_{t}\right), \quad k_{t} \equiv K_{t} / A_{t} L_{t}
$$

where $f^{\prime}>0, f^{\prime \prime}<0$, and $\lim _{k \downarrow 0} f^{\prime}(k)=+\infty$. Purely technical conditions on this and other functions are stated in appendix A. The labor market is competitive, and the wage $w_{t} \equiv W_{t} / A_{t} \bar{L}$ per unit of effective labor is

$$
w_{t} \equiv w\left(k_{t}\right)=f\left(k_{t}\right)-k_{t} f^{\prime}\left(k_{t}\right), \quad w^{\prime} \geq 0, w^{\prime \prime} \leq 0 .
$$


Capital goods are accumulated with a constant returns technology:

$$
K_{t+1}-K_{t}=G\left(I_{t}, K_{t}\right)=g\left(x_{t}\right) K_{t}, \quad x_{t} \equiv I_{t} / K_{t},
$$

where $I_{t}$ is the investment of consumption goods in capital goods production. The adjustment technology $g(x)$ satisfies $g^{\prime}>0, g^{\prime \prime}<0, g(0)=0, \lim _{x \uparrow \infty} g(x)=+\infty$, and $\lim _{x \uparrow \infty} g^{\prime}(x)=0$. Normalizing both sides of the accumulation equation by effective labor, $A_{t} L_{t}$, yields

$$
(1+\gamma) k_{t+1}=\left(1+g\left(x_{t}\right)\right) k_{t}
$$

Preferences and the saving function. Lifetime utility is a concave function of consumption during youth and old age. Each member of generation $t$ chooses the level of saving when young, $S_{t}$, that maximizes lifetime utility. The relevant features of preferences are summarized in the level of saving, $s_{t} \equiv S_{t} / A_{t} \bar{L}$, which we assume is given by

$$
s_{t}=s\left(w_{t}, r_{t}\right)
$$

where $r_{t}$ denotes the interest rate between periods $t$ and $t+1, s_{w}>0$, and $0<s_{r}<\infty$.

Capital market equilibrium. Following production in period $t$, the old sell their capital to the young at a price $q_{t}$. The young allocate their savings to the purchase of the existing stock of capital and to investment in new capital. Thus the capital market equilibrium condition is

$$
s_{t}=\left(q_{t}+x_{t}\right) k_{t} .
$$

For any level of saving, the young take the price $q_{t}$ as given and decide how much of their savings will be allocated to purchase the existing stock of capital, $k_{t}$, and how much to invest in new capital. They do so to maximize their stock of capital when old:

$$
\max _{\left\{x_{t}, k_{t}\right\}} k_{t+1} \text { s.t. }(3) \text { and (5), }
$$

which yields the standard $q$-theory condition for investment:

$$
q_{t}=\frac{1+g\left(x_{t}\right)}{g^{\prime}\left(x_{t}\right)}-x_{t}
$$

This equation implicitly defines the investment function

$$
x_{t}=x\left(q_{t}\right), \quad x^{\prime}>0 .
$$

The equilibrium interest rate can be expressed as a function of the stock of capital and its price. Replacing the saving and investment functions, (4) and (6), into the capital market equilibrium condition, (5), and substituting the wage from (1), yields

$$
r_{t}=r\left(k_{t}, q_{t}\right)
$$


It is straightforward to verify that $r_{q}>0$. We postpone discussion of the sign of $r_{k}$ to the next subsection.

Equilibrium dynamics. Equilibrium dynamics are given by the capital accumulation equation, (3), and the arbitrage condition for holding a unit of capital from $t$ to $t+1$ :

$$
\left(1+r_{t}\right) q_{t}=\left(1+G_{K}\left(I_{t}, K_{t}\right)\right)\left(q_{t+1}+F_{K}\left(K_{t+1}, A_{t+1} \bar{L}\right)\right)
$$

The right hand side of this expression is the gross return from holding the unit of capital. The only somewhat unusual term in this return derives from the adjustment cost function, as one unit of capital at time $t$ yields $1+G_{K}$ units of capital at $t+1$. Since $G_{K}=g(x)-g^{\prime}(x) x$, we will write it, with some abuse of notation, as a function of $x: G_{K}=G_{K}\langle x\rangle$. Replacing the interest rate function, (7), into the arbitrage condition, (8), and noting that $F_{K}=f^{\prime}$, the system governing equilibrium dynamics can be written as a two-dimensional system in $\left(k_{t}, q_{t}\right)$-space:

$$
\begin{aligned}
k_{t+1} & =\frac{1+g\left(x\left(q_{t}\right)\right)}{1+\gamma} k_{t} \\
q_{t+1} & =\frac{1+r\left(k_{t}, q_{t}\right)}{1+G_{K}\left\langle x\left(q_{t}\right)\right\rangle} q_{t}-f^{\prime}\left(\frac{1+g\left(x\left(q_{t}\right)\right)}{1+\gamma} k_{t}\right) .
\end{aligned}
$$

\subsection{The Growth-Saving Feedback and Speculative Growth}

A generic way to introduce feedback from expansion to saving is through the functional form of the saving function, $s(w, r)$. We assume that if the economy expands past a level $k^{o}$ of the capital stock, then the saving of the young increases sharply. We will analyze specific instances of economic phenomena that can give rise to such feedback in subsequent sections. Here we simply write the saving function as

$$
s(w, r)= \begin{cases}\widetilde{s}(w, r), & w<w\left(k^{o}\right) \\ \widetilde{s}\left(w, r+\Delta^{r}\right), & w \geq w\left(k^{o}\right)\end{cases}
$$

where $\widetilde{s}(w, r)$ is continuous in both of its arguments and $\Delta^{r}>0$. Savings jump by $\widetilde{s}_{r} \Delta^{r}$ when the wage reaches $w\left(k^{o}\right)$.

The jump in the saving function as the economy expands past $k^{o}$ translates into a dip in the equilibrium interest rate, $r(k, q)$, at $k^{o}$. Denoting by $\widetilde{r}(q, k)$ the equilibrium interest rate, as defined in $(7)$, where the saving function is $\widetilde{s}$ instead of $s$, we can write

$$
r(k, q)= \begin{cases}\widetilde{r}(k, q), & k<k^{o} \\ \widetilde{r}(k, q)-\Delta^{r}, & k \geq k^{o}\end{cases}
$$


Under weak conditions discussed in appendix A, the equilibrium interest rate is an increasing function of $k\left(r_{k}>0\right)$ everywhere except at $k=k^{o}$, where it experiences a dip.

A sufficiently strong feedback from expansion to saving gives rise to the possibility of multiple equilibrium steady states. This effect is stated formally in the following proposition:

\section{Proposition 1 (Multiple Steady States)}

There exist $\Delta^{r}>0$ and $k^{o}>0$ such that dynamic system (9)-(10) has precisely two nondegenerate steady states, $\left(k_{1}^{*}, q^{*}\right)$ and $\left(k_{2}^{*}, q^{*}\right)$, where $k_{2}^{*}>k_{1}^{*}$.

Proof: See appendix A.

To provide a detailed illustration of this proposition, figure 2 presents a heuristic phase diagram for dynamic system (9)-(10) under parameter configurations for which the result in proposition 1 holds. We start by identifying the system's steady states, which correspond to the intersection of the two stable arms, $\left\{\left(k_{t}, q_{t}\right)\right.$ s.t. $\left.k_{t+1}=k_{t}\right\}$ and $\left\{\left(k_{t}, q_{t}\right)\right.$ s.t. $\left.q_{t+1}=q_{t}\right\}$, given respectively by

$$
\begin{aligned}
g\left(x\left(q_{t}\right)\right) & =\gamma ; \\
1+r\left(k_{t}, q_{t}\right) & =\left(1+G_{K}\left\langle x\left(q_{t}\right)\right\rangle\right)\left[1+\frac{1}{q_{t}} f^{\prime}\left(\frac{1+g\left(x\left(q_{t}\right)\right)}{1+\gamma} k_{t}\right)\right] .
\end{aligned}
$$

From equation (13), the $k$-constant arm is a horizontal line that corresponds to the single level of $q_{t}$ that balances the capital accumulation rate with the economy's growth rate. On the other hand, the slope of the $q$-constant arm reflects equilibrium in the capital market. The main factor behind this schedule's negative slope is that, as the capital stock increases, the price of capital must fall because the young's ability to purchase the extra capital rises less than proportionally with the additional investment requirement. ${ }^{3}$ The exception to this slope is the upward jump in $q$ at the level $k_{t}=k^{o}$ where the saving of the young jumps up. The first intersection of the two stable arms occurs at $\left(k_{1}^{*}, q^{*}\right)$, which corresponds to the classic steady state in the Diamond model. As illustrated in figure 2, for a sufficiently large feedback from growth to saving, the jump in the $q$-constant arm will be large enough to result in a second intersection at $\left(k_{2}^{*}, q^{*}\right)$.

Turning to out-of-steady-state dynamics, figure 2 illustrates the dynamics generated by the system of difference equations, (9)-(10). There are six distinct regions, characterized

\footnotetext{
${ }^{3}$ This effect dominates everywhere except at low levels of $k$. When $k$ is small, the dominant reason for why the $q$-constant is downward sloping is that the marginal product of capital declines sharply as $k$ increases, causing its price to decline.
} 


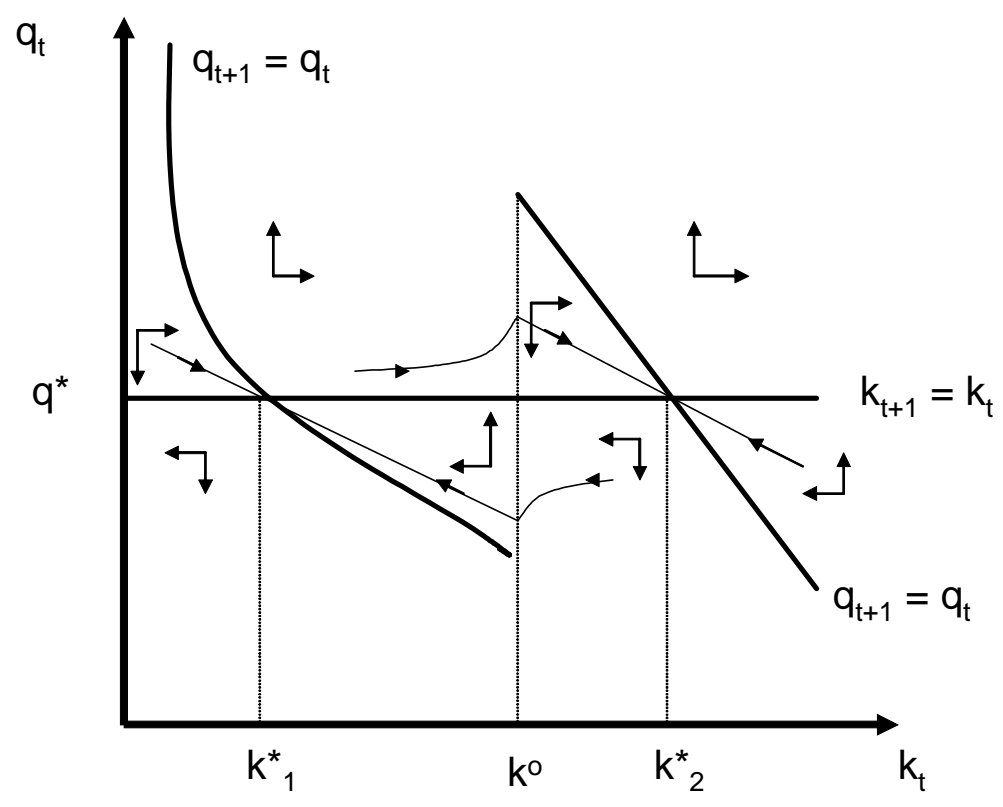

Figure 2: Dynamics in $\left(k_{t}, q_{t}\right)$-space

by the direction of movement of $k_{t}$ and $q_{t}$ over time. Each of the two steady states, $k_{1}^{*}$ and $k_{2}^{*}$, is saddle-path stable. Moreover, if $\Delta^{r}$ is large enough, the economy exhibits multiple equilibria. Starting from the same initial value for the state variable, $k$, it is possible for two equilibrium paths to arise: one that takes the economy to the high-capital steady state, $\left(k_{2}^{*}, q^{*}\right)$, and one that converges to the low-capital steady state, $\left(k_{1}^{*}, q^{*}\right)$. These two equilibrium paths are illustrated in the simulation we present next.

\subsection{Discussion}

The nature of equilibrium dynamics shown in figure 2 can be gauged from the simulation illustrated in figure 3. The specific functional forms and parameter values underlying the simulation are presented in appendix B. Starting from the initial conditions of steadystate equilibrium $\left(k_{1}^{*}, q^{*}\right)$, figure 3 illustrates an unanticipated jump at time $t=1$ to the 
equilibrium path that converges to the steady state $\left(k_{2}^{*}, q^{*}\right)$. In the same order as the empirical time series presented in figure 1, panels 3a-3d present time series for the stock market index $\left(q_{t}\right)$, the price/earnings ratio $\left(q_{t} /\left(1+G_{K}\langle x\rangle\right) f^{\prime}(k)\right)$, output growth $\left(d Y_{t} / Y_{t}\right)$, and the investment/output ratio $\left(I_{t} / Y_{t}\right)$.

a: Stock Market Index

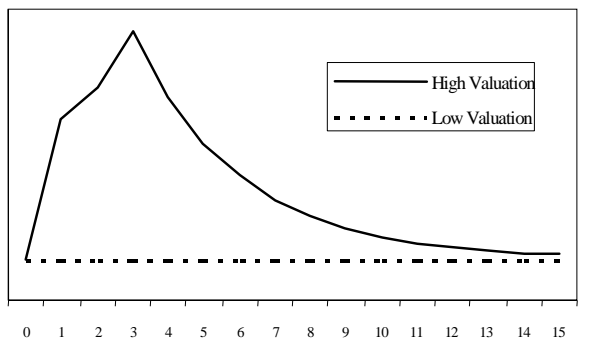

Time

c: Output Growth

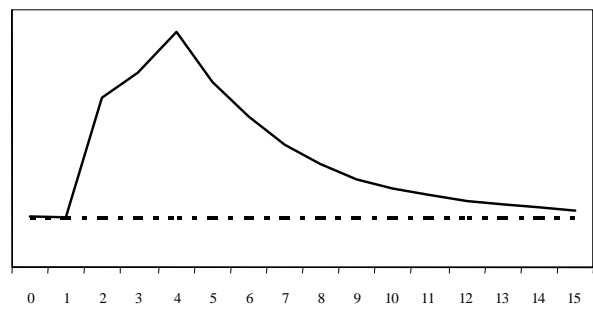

Time b: Price/Earnings Ratio

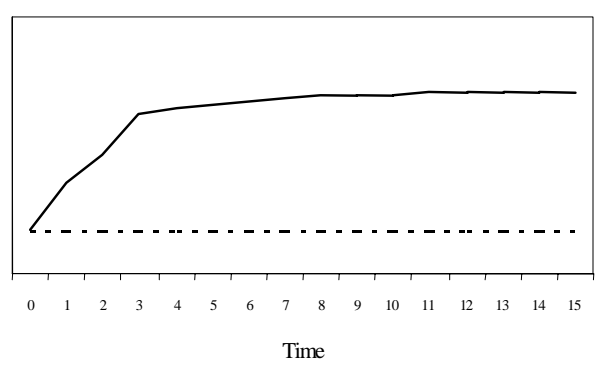

d: Investment/Output Ratio

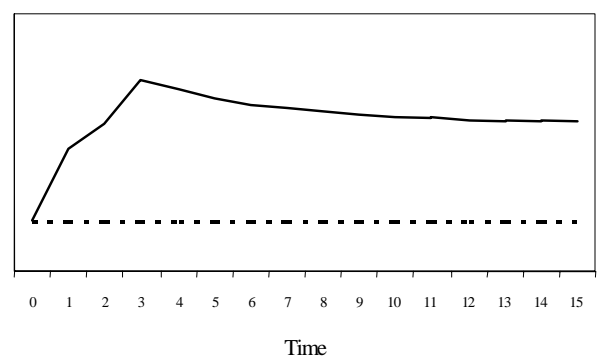

Figure 3: Low Cost-of-Capital Equilibrium

Market valuation. Starting from steady state $\left(k_{1}^{*}, q^{*}\right)$, the economy's unanticipated jump to the new equilibrium takes the form of an immediate rise in $q$ and creates a stock market windfall (panel 3a). The price of capital remains above its original level along the equilibrium path, but it converges back to that level over time. On the other hand, the market's capitalization, $q k$, converges to a higher level, since $k_{2}^{*}>k_{1}^{*}$.

When the economy moves to the new equilibrium, the key phenomenon is the rise in market valuations. We do not mean by this the absolute price level of capital or market 
capitalization, but rather their increase relative to the earnings generated by capital. As can be seen in panel $3 \mathrm{~b}$, the price/earnings ratio rises when the economy moves to the new equilibrium and continues to rise along the equilibrium path. Compared to $\left(k_{1}^{*}, q^{*}\right)$, the new steady state, $\left(k_{2}^{*}, q^{*}\right)$, exhibits a higher price/earnings ratio. What is the economic driving force behind the increase in valuations? Note from arbitrage condition (14) that, in steady state, the price/earnings ratio is the inverse of the effective cost of capital:

$$
q_{t} /\left(1+G_{K}\langle x\rangle\right) f^{\prime}(k)=1 /\left(r-G_{K}\right) .
$$

Thus, higher valuations in steady state $\left(k_{2}^{*}, q^{*}\right)$ are due to a fall in the long-term effective cost of capital.

The factor behind the increase in market valuations is the feedback from economic expansion to saving, incorporated in the jump in the saving function at $k^{o}$. This jump creates an abundance in the supply of funds and results in a decline in the effective cost of capital. The stock market boom that takes place when the economy moves to the new equilibrium reflects optimism about the future availability of funds and the cost of capital. With this in mind, we will refer to the equilibrium that converges to $\left(k_{2}^{*}, q^{*}\right)$ as the low cost-of-capital equilibrium; and to the equilibrium that converges to $\left(k_{1}^{*}, q^{*}\right)$ as the high cost-of-capital equilibrium.

Investment and growth. The low cost-of-capital equilibrium exhibits higher investment and growth than the high cost-of-capital steady state. Since $q$ is above its steady-state level along the low cost-of-capital equilibrium path, $x(q)$ is also above its steady state level and the capital stock grows to $k_{2}^{*}$. The growth in the capital stock causes an expansion in income growth during the transition (panel 3c). Over time, the growth rates of capital and income return to normal, but the low cost-of-capital steady state is characterized by permanently higher investment as a share of income (panel 3d).

Conversely, starting from the low cost-of-capital growth path, the economy could experience an unanticipated dip to a recessionary equilibrium path that takes it back to the

high cost-of-capital steady state. Along that path, the stock market crashes and triggers a slump in investment and growth as the economy rids itself of what appears ex post as widespread overcapacity.

\subsection{Bubbles as a Low Cost-of-Capital Equilibrium}

So far, our discussion deliberately made no reference to bubbles. It turns out that in our framework an equilibrium with a stock market bubble in the price $q$ of capital - 
understood as the difference between the price of an asset and its fundamental value can arise as a special case of the low cost-of-capital equilibrium described above. This kind of bubble will arise if equilibrium investment is sufficiently high that it takes the economy past a "satiation" point, where the production function is so saturated with capital that its marginal product falls to zero. Besides the difference between the price of capital and its fundamental valuation, bubbly equilibria in our model behave qualitatively the same as non-bubbly low cost-of-capital equilibria.

\section{Proposition 2 (Bubbles)}

Suppose the production function has a finite satiation point, $\bar{k}=\min \left\{k: f^{\prime}(k)=0\right\}$. There exist $\Delta^{r}>0$ and $k^{0}>0$ such that dynamic system (9)-(10) has precisely two non-degenerate steady states, $\left(k_{1}^{*}, q^{*}\right)$ and $\left(k_{2}^{*}, q^{*}\right)$, where $k_{1}^{*}<k^{0}<k_{2}^{*}$ and $k_{2}^{*} \geq \bar{k}$. Along the low costof-capital equilibrium path to $\left(k_{2}^{*}, q^{*}\right)$, the price of capital includes a bubble component and becomes a pure bubble for all $k>\bar{k}$.

Proof: See appendix A.

Intuitively, assume the production function reaches satiation at the level of capital $\bar{k}$. A bubbly low cost-of-capital equilibrium can be constructed by increasing the jump $\Delta^{r}$ in saving function (11) that drives the growth-saving feedback. This rise in saving increases the capital stock, $k_{2}^{*}$, in the low cost-of-capital steady state. If the increase in saving, $\Delta^{r}$, is large enough, $k_{2}^{*}$ crosses the satiation point, $\bar{k}$. At that point, a rational bubble emerges in the price of capital. To see this, recall that the price of capital, $q^{*}$, remains the same across all steady states, given by (13). However, the marginal product of capital for any $k_{2}^{*} \geq \bar{k}$ is zero. All output in steady state goes to labor, and the aggregate stock market generates no earnings for its owners. Thus, the positive value of $q^{*}$ corresponds to a rational bubble that is only sustained by the possibility of trading with other agents.

Thus, the bubble that can emerge in this economy can be interpreted as an extreme case of high stock market valuations driven by a low effective cost of capital.

Looking at expression (15) for the steady-state price/earnings ratio, it is apparent that as earnings decline to zero while the price of capital remains unchanged, the price/earnings ratio goes to infinity and the effective cost of capital, $r-G_{K}$, declines to zero. Moreover, if the low cost-of-capital steady state is bubbly, then the price of capital along the equilibrium path that converges to it also incorporates a bubble.

The type of bubble that arises in our model differs in several respects from the classic analysis of bubbles on non-productive assets (e.g., Tirole 1985): 
1. While bubbles on non-productive assets absorb saving away from investment, bubbles on capital can incentivize capital accumulation. ${ }^{4}$

2. In the classic analysis, by driving up the demand for saving, bubbles increase the cost of capital. The key role of the growth-saving feedback in our theory is to reverse this effect, and cause expansionary bubbles to drive down the effective cost of capital.

3. A low cost of capital increases the fundamental valuation of an asset even in the absence of a bubble. Bubbles in our model are simply an extreme case of a highvaluation equilibrium driven by a low cost of capital. Key to the continuity between the characteristics of bubbly and bubbleless equilibria is the growth-saving feedback. In the classic analysis, the introduction of a bubble raises the cost of capital and generates a macroeconomic outcome that runs counter high fundamental valuations due to a low cost of capital.

4. A central feature of the classical theory of bubbles is that they can only arise in economies whose bubbleless equilibrium is dynamically inefficient. This need not be the case in our model. The classic argument for the necessity of dynamic inefficiency runs as follows. ${ }^{5}$ Asymptotically, a bubble cannot grow faster than the economy's growth rate, $\gamma$. Otherwise, there would come a time when no agent is wealthy enough to hold it. Since a bubble must grow at the interest rate, $r$, its existence is only compatible with $r \leq \gamma$. Moreover, since the introduction of a bubble crowds out investment and, therefore, increases $r$, we must have $r<\gamma$ in the bubbleless equilibrium. This condition implies dynamic inefficiency: capital must be accumulated at a rate $\gamma$ that exceeds its return $r$, and therefore absorbs more resources than it generates. Contrary to this argument, the bubbleless equilibrium in our model need not be dynamically inefficient for a bubble to arise. The main difference comes from the fact that, in the presence of a growth-saving feedback, introducing a bubble eventually reduces $r$. Thus, it is possible to start from a dynamically efficient $(r>\gamma)$ bubbleless situation, that turns dynamically inefficient $(r<\gamma)$ as a bubble eventually lowers $r .{ }^{6}$

\footnotetext{
${ }^{4}$ See Chirinko and Schaller (2001) for evidence on the response of investment to bubbles in Japan.

${ }^{5}$ See the seminal discussion in Tirole (1985).

${ }^{6}$ Note also that the stock market bubble in our model does not need to grow at the rate of interest. The reason is that the existence of a bubble in $q$ increases the value $q G_{K}$ of the marginal improvement in capital-accumulation capacity associated with existing units of capital. Essentially, a bubble on capital generates additional bubbles on the capital this asset helps to produce.
} 
In our model, what makes a bubble emerge in the price of capital as opposed to other, non-productive assets? If the bubbleless economy is not dynamically inefficient, the only asset that might support a bubble is capital. However, it is interesting to note that once a bubble on capital arises, then it makes room for other bubbles on non-productive assets. The reason is that our bubbly equilibrium can be shown to always drive the economy into a dynamically inefficient region. ${ }^{7}$

\section{Speculation and "New Economy" Expansions}

A distinctive characteristic of the U.S. speculative expansion of the 1990s is that it was concentrated in the new technology sector. As shown in panel 4a, the stock-market price of "new economy" technology and growth companies boomed, while the price of traditional "old economy" companies did not appreciate nearly as much. Panel $4 \mathrm{~b}$ shows that during the same period the share of aggregate investment that went to technology capital experienced a sharp increase. More generally, speculative growth episodes typically have been associated with the expansion of newly emerging sectors of the economy (see, e.g., Rappoport and White 1993). This was the case during the expansion of the turn of the twentieth century, which witnessed the growth of such new sectors as railroads, steel, and oil, and during the "Roaring Twenties," which witnessed the emergence of mass-production manufacturing, electrification, automotive transportation, etc.

In this section we argue that the emergence of a new production sector is associated with a natural growth-funding feedback that provides a prime instance of the mechanisms that can support a speculative growth equilibrium. We also argue, in an endogenous growth context, that such speculative growth results in increased productivity growth.

\subsection{An Emerging-Sector Model}

We make two modifications to the model in section 2: we introduce a second production sector in addition to the one experiencing speculative growth; and we drop the ad-hoc

\footnotetext{
${ }^{7}$ To see this, recall that the effective cost of capital, $r-G_{K}$, is zero in a bubbly steady state. Since $G_{K}=g-g^{\prime} x<g$ and since, by (13), $g=\gamma$, we must have $r<\gamma$.

Also note that because of the latter, non-productive bubbles will vanish asymptotically if the stock market bubble is to survive. If that was not the case, then $r=\gamma$ and the stock market bubble could not exist. Without the latter bubble it is still possible for the non-productive one to exist, but it must leave enough space for capital to drive the economy into the dynamically inefficient region. If this is not the case, then the steady-state non-productive bubble is not feasible and only an equilibrium with a stock market bubble could survive.
} 
a: Stock Market Indices

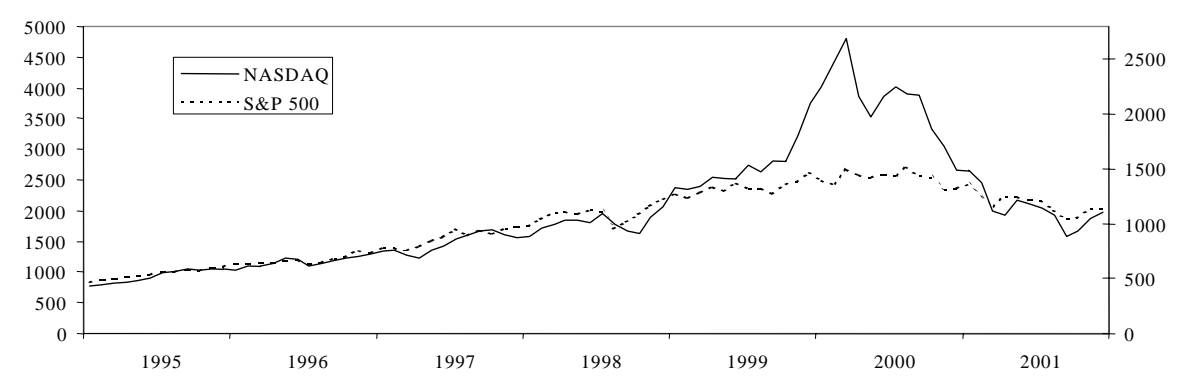

b: US Technology Investment (\% of Total)

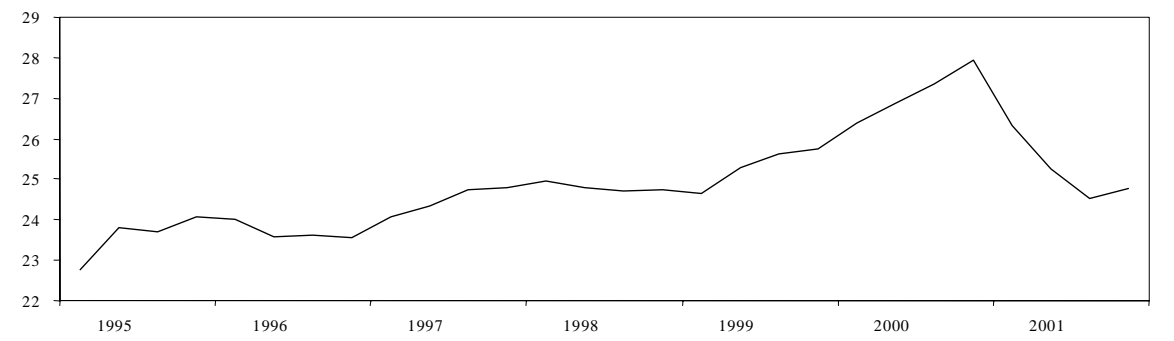

Note: Panel b: technology investment is investment on "Information processing equipment and software", which consists of computers and peripheral equipment, software, communication equipment, instruments, photocopy and related equipment and office and accounting equipment.

Sources: Panel a: Nasdaq Composite Index from The Nasdaq Stock Market, Inc; S\&P 500 Composite from Datastream. Panel b: BEA, NIPA Table 5.4.

\section{Figure 4: New Economy Boom}

assumption that the expansion-saving feedback comes from preferences. The feedback now results from the saving-generating features of the economy's emerging sector.

Old and new sectors. Recall that production in the model in section 2 uses production function $A_{t} f\left(k_{t}\right) L_{t}$, where $k_{t}$ is subject to adjustment function $g\left(x_{t}\right)$. We consider this the "new" sector, and add an "old" sector that produces the same consumption good using a different type of capital, denoted by $Z_{t}$, and labor, $L_{t}^{o}$. We assume the following old-sector production function:

$$
Y_{t}^{o}=\left\{\begin{array}{ll}
A_{t} h\left(z_{t}\right), & L_{t}^{o} \geq \bar{L}^{o} ; \\
0, & \text { otherwise; }
\end{array} \quad h^{\prime}>0, h^{\prime \prime} \leq 0,\right.
$$

where $z_{t} \equiv Z_{t} / A_{t}$. This production function allows us to capture in a concise manner the main difference between the new and the old sectors, namely that the latter has more limited 
expansion opportunities and reaches maturity earlier than the former. More precisely, expanding capital in the old sector leads to faster diminishing returns on capital (which we capture below by assuming $\left|h^{\prime \prime}\right|$ to be large enough) and benefits wages less (which we capture by eliminating any expansion opportunity in labor beyond $\bar{L}^{o}$ ). Both characteristics are key drivers of our results.

To avoid increasing the dimension of the economy's state space, we assume that consumption goods can be transformed one-to-one into $Z_{t}$ with no adjustment costs. Thus, the stock of capital in the old sector is related contemporaneously to the interest rate:

$$
h^{\prime}\left(z_{t+1}\right)=r_{t} .
$$

We also assume the old sector productive enough that we have an interior solution in the region of interest:

$$
L_{t}^{o}=\bar{L}^{o}
$$

In this case, the wage rate in the old sector is equal to the marginal product of labor in the new sector, $w_{t}$. Also, labor employed in the new sector now differs from the total labor force, and is equal to $L=\bar{L}-\bar{L}^{o}=(1-\lambda) \bar{L}$, where $\lambda \equiv \bar{L}^{o} / \bar{L}$.

Growth-saving feedback. The second modification we make to the model in section 2 is to drop the assumption of a jump in the saving function and assume a more conventional undiscounted log-utility function. ${ }^{8}$ As is well known, this assumption implies the following saving function for the young:

$$
s_{t}=\frac{1}{2} w_{t}
$$

The feedback from expansion to saving no longer comes from the structure of preferences, but from the saving-generating features of the new sector. As in section 2, capital market equilibrium allows us to derive the interest rate $r_{t}=r\left(k_{t}, q_{t}\right)$ as a function of the newsector capital stock and its price. In equilibrium, the young's saving must be equal to their investment in the two capital stocks:

$$
s_{t}=(1+\gamma) z_{t+1}+\left(x\left(q_{t}\right)+q_{t}\right)(1-\lambda) k_{t} .
$$

Given saving function (17), the saving surplus that can be used to fund old-sector capital is therefore

$$
z_{t+1}=(1+\gamma)^{-1}\left[\frac{1}{2} w\left(k_{t}\right)-\left(x\left(q_{t}\right)+q_{t}\right)(1-\lambda) k_{t}\right] .
$$

\footnotetext{
${ }^{8}$ Note that diminishing returns in the old-sector production function implies the presence of rents, which effectively accrue to quasi-factors of production. We assume that these quasi-factors do not save.
} 
The top panel of figure 5 illustrates the young's total saving and their investment in the new sector as a function of $k_{t}$; the middle panel illustrates the saving surplus into the old sector that results from the difference between the two. Note that concavity of the wage function, $w\left(k_{t}\right)$, means that the saving surplus is initially increasing then decreasing in $k_{t}$. It is along the segment where the saving surplus is increasing that the economy exhibits feedback from expansion in the new sector (as measured by $k_{t}$ ) and saving (as measured by the surplus).

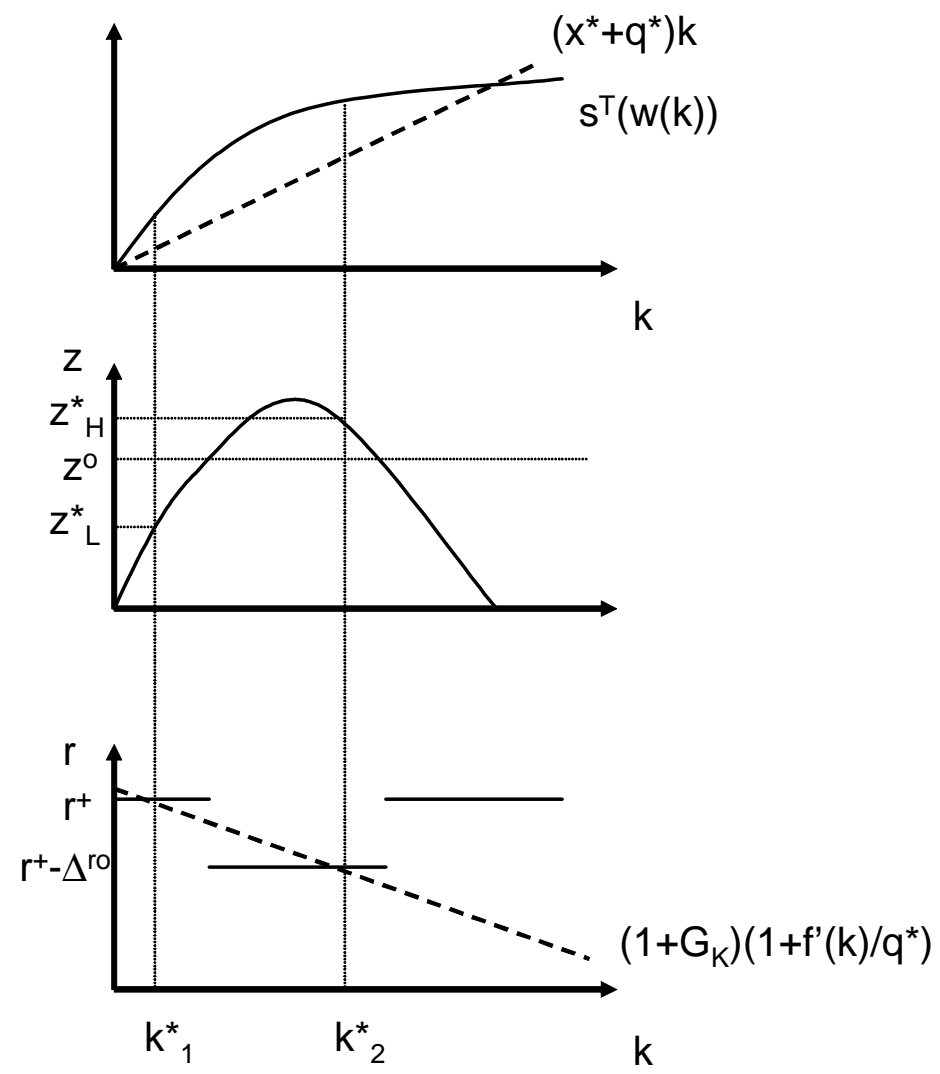

Figure 5: Equilibria

The positive feedback from growth to saving induces a negative feedback from growth to the interest rate, $r_{t}$. To see this, note that by first-order condition (16) the saving surplus determines interest rate function $r_{t}=r\left(k_{t}, q_{t}\right)$. While the interest rate function in section 2 was driven by preferences that exhibit an interest-elasticity of saving, it is here driven by investment opportunities in the old sector. Because of diminishing returns to capital, a 
higher surplus results in a lower interest rate. Thus, for low $k_{t}$, expanding the new sector generates more saving than it uses and reduces the interest rate; for high $k_{t}$, it generates less saving than it uses and increases the interest rate. Given the interest rate function, $r\left(k_{t}, q_{t}\right)$, the model can then be solved exactly as in section 2 , with equilibrium dynamics given by the system, (9)-(10). ${ }^{9}$

Multiple equilibria. The grow-saving feedback opens the possibility for multiple equilibria through the emergence of a low cost-of-capital equilibrium. We show this possibility under a special functional form that preserves the stark discontinuity of the model in section 2 and highlights the parallels with that model. We assume that the old-sector production function, $h(z)$, is piece-wise linear:

$$
h\left(z_{t}\right)= \begin{cases}r^{+} z_{t}, & z_{t}<z^{o} \\ r^{+} z^{o}+\left(r^{+}-\Delta^{r o}\right)\left(z_{t}-z^{o}\right), & \text { otherwise }\end{cases}
$$

where $\left.\Delta^{r o} \in\right] 0, r^{+}[$measures the degree of diminishing returns in the old sector. From (16), this functional form results in two possible levels of the interest rate, depending on whether $z_{t}$ is smaller or greater than $z^{o}$. Given the inverted U-shaped form of the surplus function in the middle panel of figure 5 , there are two levels of $k_{t}, \widetilde{k}^{l}\left(q_{t}\right)$ and $\widetilde{k}^{u}\left(q_{t}\right)$, such that surplus (19) equals $z^{o}$. Thus, as illustrated in the bottom panel of figure 5 , the interest rate is given by

$$
r\left(k_{t}, q_{t}\right)= \begin{cases}r^{+}, & k_{t}<\widetilde{k}^{l}\left(q_{t}\right) \quad \text { and } \quad k_{t}>\widetilde{k}^{u}\left(q_{t}\right) \\ r^{+}-\Delta^{r o}, & \text { otherwise. }\end{cases}
$$

The range of $k_{t}$ in which the interest rate dips corresponds to the range where the growthsaving feedback is positive and the saving surplus is increasing; and the range of $k_{t}$ in which the interest rate jumps back up corresponds to the range where the saving surplus is decreasing.

The following proposition establishes the possibility of multiple steady states:

\section{Proposition 3 (Multiple Steady States)}

There exist $r^{+}>0, \Delta^{r o}>0$ and $z^{o}>0$ such that dynamic system (9)-(10) has precisely two non-degenerate steady states, $\left(k_{1}^{*}, q^{*}\right)$ and $\left(k_{2}^{*}, q^{*}\right)$, where $k_{2}^{*}>k_{1}^{*}$.

\footnotetext{
${ }^{9}$ Note that since (16) allows us to solve out for $z_{t+1}$ as a function of the interest rate, we can focus directly on the saving that goes into the new sector, defined as $s_{t}^{k} \equiv s_{t}-(1+\gamma) z_{t+1}$. By (16)-(18), it is given by $s_{t}^{k}=\frac{1}{2} w_{t}-(1+\gamma)\left(h^{\prime}\right)^{-1}\left(r_{t}\right) \equiv s^{k}\left(w_{t}, r_{t}\right)$, with $s_{w}^{k}>0$ and $s_{r}^{k}>0$. Having solved out for the old-sector capital stock, we obtain a saving function into the new sector that is similar to function (4) in section 2. However, the difference is that the positive interest-elasticity of $s^{k}\left(w_{t}, r_{t}\right)$ does not come from preferences, but from the possibility of reallocating saving from the old to the new sector.
} 
Proof: See appendix C.

To illustrate the emergence of multiple steady states, consider steady-state conditions (13)-(14). Equation (13) equates $q_{t}$ to the level $q^{*}$ that balances the capital accumulation rate with the economy's growth rate. Equation (14) is an arbitrage condition that equates the interest rate $r\left(k_{t}, q_{t}\right)$ to the marginal return from investing in a unit of $k_{t}$. As illustrated by the dashed line in the bottom panel of figure 5, this marginal return is decreasing in $k_{t}$ because of diminishing returns in the new sector. Given $q_{t}=q^{*}$, a steady state is the intersection of the dashed line with the interest rate function. As shown in the figure, in addition to steady state $\left(k_{1}^{*}, q^{*}\right)$, the economy can exhibit a second steady state, $\left(k_{2}^{*}, q^{*}\right)$, characterized by a low cost of capital. This will happen if the growth-saving feedback is sufficiently strong in the sense that the dip in the interest rate (given by the measure $\Delta^{r o}$ of diminishing returns in the old sector) be large enough compared to the slope of the dashed line (given by the degree of diminishing returns in the new sector). This condition captures the idea that the new sector is immature relative to the old sector, in the sense that it exhibits a relatively low degree of diminishing returns. If this were not the case, the old sector would compete for saving with the new sector and would cause the interest rate to rise relative to the new sector's marginal product. This would prevent a sufficient fall in the effective cost of capital that is behind the second steady state. ${ }^{10}$

Equilibrium dynamics in the presence of multiple steady states are illustrated in figure 6. The heuristic phase diagram in this figure is similar to that in figure 2 of section $2 .{ }^{11}$ The one difference is that, because now the discontinuity in the interest rate function $r\left(k_{t}, q_{t}\right)$ also depends on $q$, the phase diagram exhibits a discontinuity around the rising segment of the $q$-stable arm — which, strictly speaking, does not exist in this case. This technicality does not affect our analysis of equilibrium or dynamics. ${ }^{12}$ As before, there are two saddlepath stable steady states: $\left(k_{1}^{*}, q^{*}\right)$ and $\left(k_{2}^{*}, q^{*}\right)$. Both are associated with the same price of capital, $q^{*}$. However, $\left(k_{2}^{*}, q^{*}\right)$ exhibits a lower effective cost of capital than $\left(k_{1}^{*}, q^{*}\right)$.

A numerical simulation similar to that in section 2 can show that this economy exhibits

\footnotetext{
${ }^{10}$ Another factor behind multiple equilibria in our model is the fact that expanding the new sector generates more income for saving than the old sector. In our model, the type of income that generates saving is the labor income of the young, but more generally this could also correspond to profits.

${ }^{11}$ If $k_{1}^{*}<\widetilde{k}^{l}\left(q^{*}\right)$, which we assume, there can be no equilibrium in the region $k>\widetilde{k}^{u}\left(q^{*}\right)$. The reason is that in this region the $q$-stable arm is the continuation of the same arm for $k<\widetilde{k}^{u}\left(q^{*}\right)$, which is monotonically decreasing and has already intersected the $k$-stable arm at $k_{1}^{*}$.

${ }^{12}$ For the latter, there is still a well defined value of $q$, for any given $k$ in that region, such that dynamics change from those below an (imaginary) $q$-constant arm to those above it.
} 


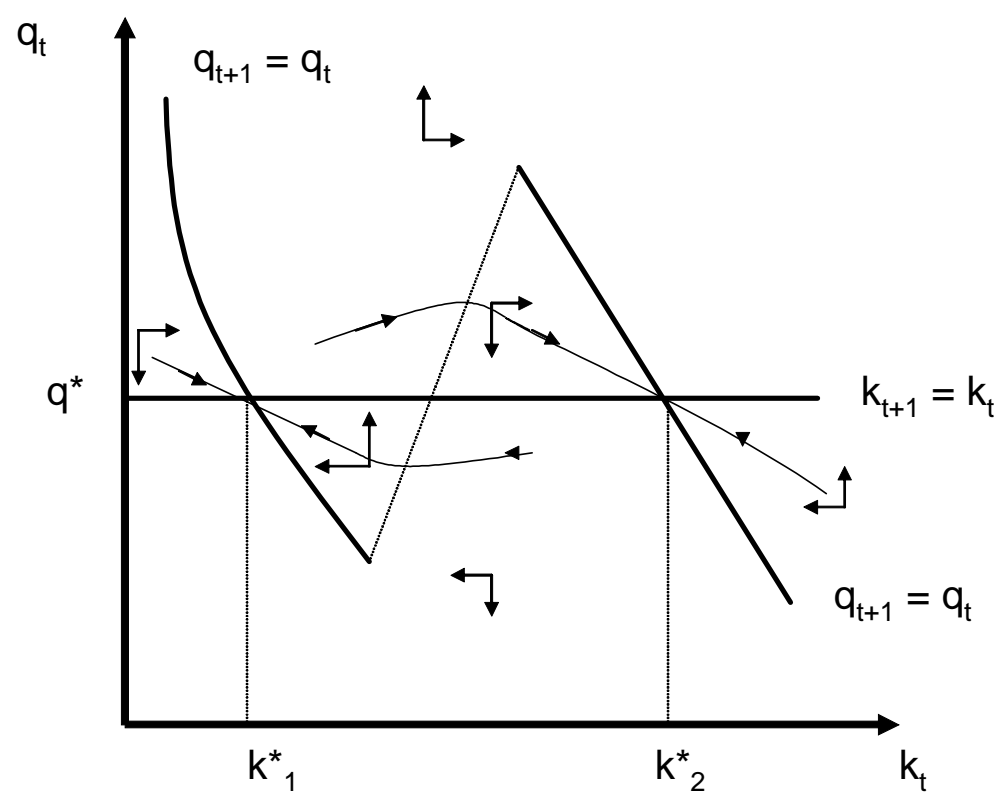

Figure 6: The Two-sector Model

multiple equilibria starting from the low steady state level of capital, $k_{1}^{*} \cdot{ }^{13}$ What determines transitional dynamics along a speculative growth expansion? Suppose the economy starts at $k_{t}=k_{1}^{*}$ and experiences an unanticipated jump onto the equilibrium path that converges to $\left(k_{2}^{*}, q^{*}\right)$. Sector reallocation plays an important role in this transition. The immediate increase in capital accumulation in the new sector is caused by the reallocation of capital from the old sector to the new accompanied by a jump in $q_{t}$, combined with an initial increase in the interest rate. ${ }^{14}$ As the new sector expands, it starts generating a saving surplus that helps restore resources to the old sector and reverses the hike in the interest rate (increases

\footnotetext{
${ }^{13}$ The results of the simulation are available from the authors upon request.

${ }^{14}$ Interestingly, had we introduced adjustment costs to the old-sector capital stock, $z_{t}$, the initial impact of jump to the speculative equilibrium path would include a drop in the price of old-sector capital, which is reminiscent of the behavior of the stock price of "old economy" companies in the US expansion of the late 1990 s.
} 


\section{Table 1: US Multifactor Productivity Growth}

\begin{tabular}{lc}
\hline \hline time period & growth rate $(\%$, annualized) \\
\hline $1981-1985$ & 0.51 \\
$1986-1990$ & 0.52 \\
$1991-1995$ & 0.58 \\
$1996-2000$ & 1.21 \\
\hline $\begin{array}{l}\text { Note: Multifactor Productivity is for the Private Nonfarm Business sector. } \\
\text { Source: Bureau of Labor Statistics. }\end{array}$
\end{tabular}

$z_{t}$ past $z^{o}$ in our piece-wise linear model). Ultimately, as the economy converges to $\left(k_{2}^{*}, q^{*}\right)$, the old sector expands beyond its initial capital stock and the cost of capital falls below its initial level.

\subsection{Technology Bubbles}

The U.S. speculative expansion of the 1990s not only was concentrated in the technology sector, but also was associated with an increase in productivity growth beyond what is attributable to pro-cyclical productivity (e.g., Baily and Lawrence 2001). Table 1 presents average multifactor productivity growth for the U.S. economy in subsequent five-year intervals. It illustrates the acceleration of productivity growth in the second half of the 1990s. This type of evidence formed the basis for the case that the U.S. expansion was not caused by market speculation, but rather by underlying fundamentals that pointed to a technological revolution (e.g., Greenwood and Jovanovic, 1999; Hobijn and Jovanovic, 2000). To address this issue, we endogenize growth in our two-sector model and show that the speculative growth equilibrium is associated with higher productivity growth. Moreover, we show that increased productivity growth provides increased future income, which fuels the key feedback from growth to saving. Thus, increased productivity growth is not only a result of market speculation, but also can play a central role in the mechanisms that make a speculative equilibrium possible. In our model, a technological revolution can be considered an integral part - both as cause and consequence - of a speculative growth equilibrium. Endogenizing growth. In order to endogenize growth, we modify the production functions in our two-sector model. We now assume linear production functions in the two sectors, set $\Delta^{r o}=\lambda=0$, and write aggregate output as

$$
Y_{t}=\bar{A} K_{t}^{e} L+r^{+} Z_{t}, \quad \bar{A}, r^{+}>0 .
$$

As before, an expansion in $K$ benefits labor (savers) while an expansion in $Z$ does not. We 
interpret $K_{t}$ as "technology" capital, subject to standard external spillovers, and make the extreme assumption that $K_{t}$ enters as a pure externality in production, which is indicated by the superscript $e$ on $K_{t}^{e}$. Because $K_{t}$ enters as a pure externality, its private fundamental value is $q^{f} \equiv 0$. However, its price may be higher than $q^{f}$ and incorporate a bubble. As before, $K_{t}$ is accumulated according to (2), subject to adjustment costs; and $Z_{t}$ is subject to no adjustment costs.

Accumulation of $K_{t}$ is still determined by the $q$-theory relationship, $x_{t}=x\left(q_{t}\right)$. In the absence of a private dividend, arbitrage equation (8) governing $q_{t}$ becomes

$$
\left(1+r_{t}\right) q_{t}=\left(1+G_{K}\left\langle x\left(q_{t}\right)\right\rangle\right) q_{t+1}
$$

As long as $Z_{t}>0$, the interest rate is equal to the marginal product of $Z_{t}$ :

$$
r_{t}=r^{+}
$$

Finally, since the wage is $\bar{A} K_{t}^{e}$, our assumption of undiscounted log-utility implies that saving is $\frac{1}{2} \bar{A} K_{t}^{e}$, and the capital-market equilibrium condition is

$$
\frac{1}{2} \bar{A} K_{t}^{e}=Z_{t+1}+\left(x\left(q_{t}\right)+q_{t}\right) K_{t}^{e}
$$

Speculative growth. Starting from an initial stock $K_{0}^{e}>0$, this economy can exhibit two equilibria: a low-valuation equilibrium that corresponds to fundamental-value pricing of technology, $q^{f}=0$; and a high-valuation equilibrium that incorporates a bubble $q_{t}^{*}>0$ in the price of technology. Under the former equilibrium (denoted by " $L$ "), $x_{L}^{*}=x(0)=0$ and $K_{L}^{e *} \equiv K_{0}^{e}$ is not accumulated. $Z_{L}^{*}=\frac{1}{2} \bar{A} K_{0}^{e}$ is determined by capital-market equilibrium condition (22) and, by the normalization $L=1$, aggregate output is

$$
Y_{L}^{*}=\left(1+\frac{1}{2} r^{+}\right) \bar{A} K_{0}^{e}
$$

This equilibrium exhibits no productivity growth and no capital accumulation over time. It is dynamically efficient since $r^{+}>\gamma=0$.

Under the high-valuation equilibrium (denoted by " $H$ "), as long as $Z_{H t}^{*}$ is positive, (20) and (22) imply that $G_{K}\left\langle x\left(q_{t}^{*}\right)\right\rangle \equiv r^{+}$. The bubble is therefore equal to $q_{t}^{*} \equiv x^{-1}\left(G_{K}^{-1}\left\langle r^{+}\right\rangle\right)$ and $x_{H t}^{*} \equiv G_{K}^{-1}\left\langle r^{+}\right\rangle$. By $(2), K_{t}^{e}$ grows at rate $\gamma_{H}^{*}=g\left(x_{H}^{*}\right)$. Capital-market equilibrium condition (22) implies that $Z_{H t+1}^{*}=\left(\frac{1}{2} \bar{A}-x_{H}^{*}-q^{*}\right) K_{t}^{e}$ and grows at the same rate as $K_{H t}^{e *}$. $Z_{H t}^{*}$ is positive if $\bar{A}>2\left(x_{H}^{*}-q^{*}\right)$, which we assume. Aggregate output is given by

$$
Y_{H t}^{*}=\left[\bar{A}+\frac{r^{+}}{1+\gamma_{H}^{*}}\left(\frac{1}{2} \bar{A}-x_{H}^{*}-q^{*}\right)\right] K_{H t}^{e *} .
$$


Thus, in the high-valuation equilibrium, productivity and output grow at endogenous rate $\gamma_{H}^{*}$.

Figure 7 illustrates these two equilibria.

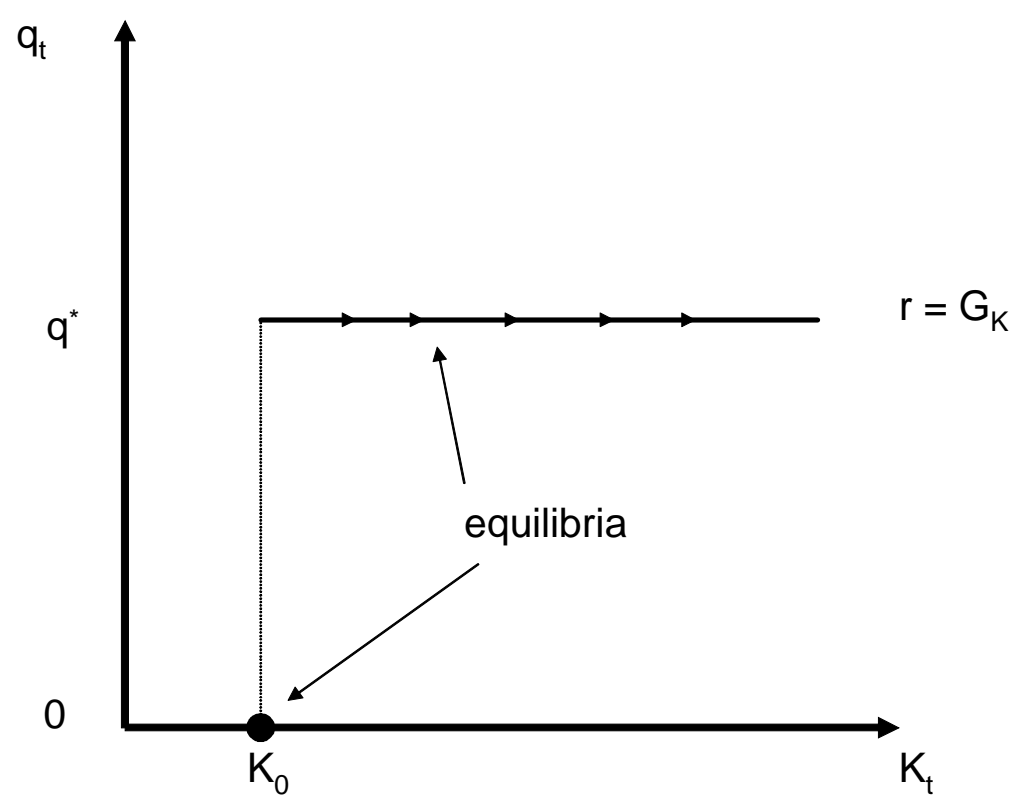

Figure 7: Endogenous Growth Model

Discussion. This model provides a stark example of speculative equilibrium that results in sustained endogenous growth. Even though neither the $K$-sector nor the $Z$-sector are subject to social diminishing returns, only the former can be the engine of growth. The reason is that it is the only one that can generate the feedback from growth to saving necessary to fund investment along the balanced growth path. In the low-valuation trap, all saving is trapped in the $Z$-sector, which does not generate more saving as it grows. If the economy moves to the high-valuation equilibrium and incentivizes technology accumulation, saving shifts to the technology sector which will create more saving as it grows. This growth-saving feedback emerges through the technological spillover associated with technology investment, 
as productivity growth increases the income of savers. The feedback reduces the effective cost of capital, $r-G_{K}$, and gives rise to a high-valuation equilibrium.

Two aspects of the high-valuation equilibrium are worth noting. First, unlike our previous models, here the fall in the effective cost of capital does not occur through a fall in the interest rate, which is equal to a constant, $r^{+}$. High valuations in the stock market will not be reflected by high valuations in the bond market. The reduction in the effective cost of capital takes the form of an increase in the flow-value, $q G_{K}$, offered by capital in opening opportunities for profitable investment. This value increases along with the increase in the investment ratio, $x$. Put differently, the speculative increase in the valuation of technology is not associated with a fall in the interest rate, but rather with an increase in the value of future investment opportunities opened by technology. This increase in value is tightly linked with the high pace of investment in the high-valuation equilibrium.

Second, the effective cost of capital in the high-valuation equilibrium falls to an extreme level, $\bar{r}-G_{K}=0$, consistent with the emergence of a technology bubble. In the presence of externalities, such a bubble - if sustainable - can enhance welfare. Speculation of this type can substitute for well-functioning markets and can encourage investment and growth. Obviously, the risk is that the bubble may crash and trigger a crisis, an aspect we do not model in this paper.

\section{$4 \quad$ Public and Foreign Saving}

Starting from the initial conditions of the low-valuation steady state in the models of sections 2 and 3, the high-valuation equilibrium implies an investment boom. For this investment boom to materialize, it is important that it be supported by an increase in saving both in the short term and in the long term. ${ }^{15}$

Both models, whether we consider the short or the long run, rely on an increase in private domestic saving. Of course, this is only one of the possible saving channels that can fund investment. Figure 7 depicts the saving channels that funded the investment booms associated with the Nikkei and the Nasdaq bubbles. The investment boom in both episodes actually was accompanied by a decline in private domestic saving. The main funding sources were government budget surpluses and the current account. This evidence relates to the funding of investment at the inception and "early" stages of the speculative expansion. Since the bubbles burst in this case, we have no direct evidence on the long-term

\footnotetext{
${ }^{15}$ Strictly, the model in section 3 does not need an increase in aggregate saving at impact since reallocation from old to new sector is possible.
} 
a: United States

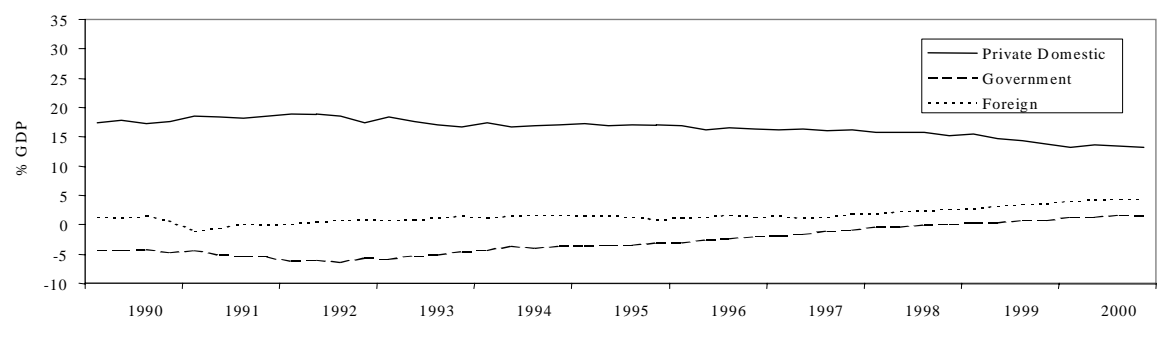

b: Japan

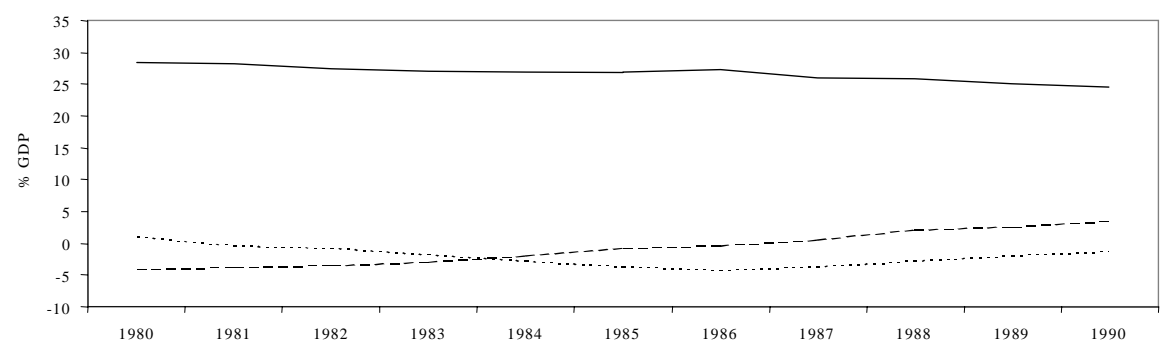

Notes: Panel a: private domestic saving is "Gross Private Saving"; government saving is "Gross Government Saving" minus "Gross Government Investment"; foreign saving is minus "Net Foreign Investment". Panel b: for each domestic sector, gross saving is used which is defined as the sum of "Saving", "Consumption of fixed capital" and "Capital transfer etc. net"; foreign saving is minus "Net lending to the rest of the world".

Sources: Panel a: BEA, NIPA Table 5.1. Panel b: Annual report on national accounts (CD-ROM) 1998.

Figure 8: Saving Channels

sources of funding, which are at the core of the theory.

Guided by the short-run evidence and its relevance for the policy debate, this section focuses on two alternatives to domestic private saving in supporting speculative growth: government saving and the current account.

\subsection{Fiscal Policy and Surplus Illusion}

The fiscal surpluses generated during the Japanese and U.S. speculative growth experiences were the combined result of fiscal consolidation measures and the automatic effect of procyclical tax revenues in a booming environment. The reduction in public debt had a moderating effect on interest rates in the short run and substituted for increased private saving to fund the investment boom. It is in this sense that a tight policy of paying down 
the national debt supported the boom in the short term. Turning to the more novel issue of longer-term sustainability, and hence to a necessary condition for a rational speculative growth episode, we argue that a continuing policy rule of generating fiscal surpluses provides critical support to the high-valuation equilibrium.

To develop our argument, we add a government to the first model of section 3 (with $\lambda=0$ ). We assume the government taxes wage income at a rate $\tau_{t}$ and spends $g_{t} A_{t} L$ on goods that do not enter agents' utility function. Thus the government's budget constraint is

$$
(1+\gamma) d_{t+1}=\left(1+r_{t}\right) d_{t}-\left(\tau_{t} w_{t}-g_{t}\right)
$$

where $d_{t} \equiv D_{t} / A_{t} L$ denotes public debt per unit of effective labor.

Adding the public sector alters two equations in the model. The saving of the young net of investment in $z, s_{t}^{k}$, is now a function of after-tax wages:

$$
s_{t}^{k}=s^{k}\left(\left(1-\tau_{t}\right) w\left(k_{t}\right), r_{t}\right),
$$

while the capital-market equilibrium condition is now given by

$$
\left(\tau_{t} w_{t}-g_{t}-r_{t} d_{t}\right)+s_{t}^{k}=d_{t}+\left(q_{t}+x\left(q_{t}\right)\right) k_{t} .
$$

The saving of the government and of the young must fund the purchase of the existing public debt and capital stock from the old as well as funding new investment. Combined, equations (24)-(25) implicitly define a new interest rate function $r_{t}=r\left(k_{t}, q_{t}, d_{t}, \tau_{t}, g_{t}\right)$. The economy's dynamics are described by system (9)-(10) with the new interest rate function together with the government budget constraint, (23), and a fiscal policy rule.

Let us consider a benchmark fixed-parameters policy rule under which detrended government spending and the tax rate are fixed at $\bar{g}>0$ and $\bar{\tau}>0$. To facilitate comparisons, we assume that this and other policy rules result in a balanced budget in the low-valuation steady state — which requires $\bar{g}=\bar{\tau} w_{1}^{*}$ - and, therefore, result in the same low valuation steady state. The important point to notice is that this fixed-parameters policy creates primary surpluses during expansions beyond $k_{1}^{*}$ and primary deficits during contractions. To see this, note that the fiscal rule implies that the primary government surplus, $\left(\bar{\tau} w_{t}-\bar{g}\right)$, increases with $w_{t}$ in an expansion. Thus the response of the combined "gross" saving of government and the young to an increase in wages is given by $\left(\bar{\tau}+s_{w}^{k}(1-\bar{\tau})\right) d w_{t}$. As long as the young's marginal propensity to save is less than one $\left(s_{w}^{k}<1\right)$, which we assumed, the fixed-parameter rule generates surpluses as the wage rises. 
The increase in saving generated by the fixed-parameters rule not only facilitates the funding of investment in the short run but, more importantly, plays a central role in facilitating the emergence of a speculative growth scenario. This feasibility point is made most clearly by focusing on the low cost-of-capital steady state, $\left(k_{2}^{*}, q^{*}\right)$, rather than on the entire path. One can show easily that if, instead of being fixed, government spending is raised with the endogenous increase in the wage, then aggregate saving falls and so does the level of $k_{2}^{*}$. In fact this fiscal expansion experiment is similar to reducing $\Delta^{r}$ in section 2. For a high enough indexation of fiscal spending to wages, the high investment equilibrium is no longer feasible. In other words, fiscal surpluses are not only a symptom of the speculative growth episode, but also can be a central element of the factors that support it.

The notion that the fiscal surpluses generated by the speculative equilibrium can be partly spent or rebated to the taxpayer may be an illusion. The surpluses could be a pillar of the speculative equilibrium, and might swiftly disappear if this equilibrium unravels giving rise to what one might term as a surplus illusion.

\section{Proposition 4 (Surplus Illusion)}

Let $g_{t}=\bar{g}+\alpha \bar{\tau}\left(w_{t}-w_{1}^{*}\right)$. If the economy has two saddle-path steady state equilibria for $\alpha=0$, there exists an $\alpha^{m}>0$ such that for any $\alpha \geq \alpha^{m}$, the high valuation equilibrium disappears.

Proof: See appendix D.

\subsection{The Current Account}

The second major source of funding for the investment boom in Japan and the U.S. was the current account. As a short-term funding mechanism, international capital flows can moderate the rise in interest rates needed to fund the investment boom. ${ }^{16}$ Over time, the whole world may be dragged into a speculative path, with the home economy becoming the chronic recipient of external resources.

A simple reinterpretation of the model in section 2 (or 3) helps isolate these short and long run aspects of capital inflows. For this purpose, let domestic residents now correspond to the old at time 0 , and assume they owe foreigners $b_{0} A_{0} L=q^{*} k_{1}^{*} A_{0} L$. All future (active)

\footnotetext{
${ }^{16}$ Ventura (2001) describes an interesting alternative portfolio channel connecting the current account and a domestic bubble. In his model, the main effect of the bubble is to raise domestic wealth. As domestic agents attempt to rebalance their portfolios by investing in non-bubbly domestic equity, external borrowing rises to finance the investment that is required to build domestic equity.
} 
generations are foreigners that live abroad and export to the domestic economy intermediate inputs with 100 percent labor content, measured by L. Only the domestic economy accumulates capital, $K_{t}$. Except for the labeling of the intergenerational flows, this model can be analyzed in exactly the same way as the model in section 2 . Net exports correspond to $A_{0} L f\left(k_{0}\right)-I_{0}-\left(q_{0} K_{0}-b_{0} A_{0} L\right)$ at date 0 and $A_{t} L f\left(k_{t}\right)-I_{t}$ thereafter.

Let us use as a benchmark the low-valuation steady state, where the economy experiences de-trended trade surpluses $f\left(k_{1}^{*}\right)-x^{*} k_{1}^{*}$ for the indefinite future. Now suppose that, starting at the same level of capital, $k_{1}^{*}$, the price of capital jumps to a speculative growth path. Domestic residents sell the spread, $\left(q_{0}-q^{*}\right) k_{1}^{*} A_{0} L_{0}$, to foreigners and consume the proceeds. Thus the stock market rise fuels a domestic consumption boom financed by foreign capital inflows. The new high-investment equilibrium is then financed fully by foreigners. If the high-valuation equilibrium is dynamically inefficient, then net exports are asymptotically negative, and the domestic economy becomes a resource sink for foreigners. The current account remains negative throughout and, again, becomes an integral part of the speculative growth episode.

\section{Final Remarks}

This paper builds a theoretical framework for thinking about episodes of speculative growth. We characterize this phenomenon as a low effective cost-of-capital equilibrium based on optimism about the future availability of funds for investment. Our framework highlights the key short-term and long-term funding mechanisms necessary to sustain a speculative growth equilibrium. The emergence of a new sector, fiscal surpluses, or current account deficits not only are possible consequences of a high-investment equilibrium, but also are central to generating the saving necessary to support it.

Ours is not a framework of "irrational exuberance," although it offers a natural interpretation of such episodes. These occur when a speculative growth path is not backed by a long-run funding mechanism strong enough to eventually validate the explosive capital gains dynamics that are needed in the short run to reallocate resources toward the sectors that drive the boom. A prototypical example of such a scenario is when a bubble attaches to the "wrong" sector, as it may have been the case in Japan during the 1980s with its large real estate boom.

The U.S. experience during the 1990s probably had elements of both: A rational speculative growth component built on the information technology sector, sound fiscal policy, and foreigners' confidence, as well as some elements of irrationality during the late 1990s. 
From this perspective, it is not at all clear whether much of the U.S. asset markets boom during the 1990s, even if bubbly, was comdemned to be reversed. In fact, there is a case to be made for attempting to restart such process rather than letting the economy dwindle toward the pre-1990s capital/output ratios. Our framework highlights the importance of fostering long-run funding mechanisms and technology in achieving such goal. 


\section{A Proof of Propositions in Section 2}

First we give a summary of the assumption made in the text, supplementing them by some technical conditions.

Assumption 1 The production function $f: \mathbf{R}_{+} \rightarrow \mathbf{R}_{+}$is three times differentiable and satisfies

1. $\lim _{k \downarrow 0} f^{\prime}(k)=+\infty, \lim _{k \uparrow \infty} f^{\prime}(k)=0, \lim _{k \downarrow 0} w^{\prime}(k)=+\infty, \lim _{k \uparrow \infty} w^{\prime}(k)=0$, and

2. $f^{\prime}(k) \geq 0, f^{\prime \prime}(k) \leq 0, w^{\prime}(k) \geq 0, w^{\prime \prime}(k) \leq 0$ for all $\mathbf{R}_{+}$,

3. for $k \in \mathbf{R}_{+}, f^{\prime}(k)>0$ implies $f^{\prime \prime}(k)<0$ and $w^{\prime}(k)>0$ implies $w^{\prime \prime}(k)<0$,

where $w(k)=f(k)-f^{\prime}(k) k$.

Assumption $\mathbf{2}$ The function $\widetilde{s}: \mathbf{R}_{+} \times[-1,+\infty) \rightarrow \mathbf{R}_{+}$is continuously differentiable and satisfies

1. $0<\widetilde{s}_{w}(w, r) \leq 1,0<\widetilde{s}_{r}(w, r)<\infty$,

2. $\lim _{r \rightarrow \infty} \widetilde{s}(w, r)=w$ for all $w \in \mathbf{R}_{+}$,

3. $\widetilde{s}(w,-1)=0$ for all $w \in \mathbf{R}_{+}$.

In the main text it was pointed out that under weak conditions $r_{k}(k, q)>0$ in all relevant regions except at points with $k=k^{o}$. We will simplify the analysis further here with a condition that ensures that this holds everywhere but at points with $k=k^{o}$.

Assumption 3 The production function $f$ and the function $\widetilde{s}$ satisfy

$$
\left(\frac{\widetilde{s}_{w}(w(k), r) w(k)}{\widetilde{s}(w(k), r)}\right) \cdot\left(\frac{w^{\prime}(k) k}{w(k)}\right)<1
$$

for all $k \in \mathbf{R}_{+}$and $r \in(-1,+\infty)$.

Assumption 4 The adjustment cost function $g: \mathbf{R} \rightarrow \mathbf{R}$ is twice continuously differentiable and satisfies

1. $g(0)=0, \lim _{x \uparrow \infty} g(x)=\infty$,

2. $g^{\prime}(x)>0$ for all $x \in \mathbf{R}$ and $g^{\prime}(0)=1$,

3. $\lim _{x \uparrow \infty} g^{\prime}(x)=0$, 
4. $g^{\prime \prime}(x)<0$ for all $x \in \mathbf{R}$.

Assumption 5 The rate of technological progress is nonnegative, that is $\gamma \geq 0$.

Proposition 1 Under assumptions 1-5, there exists $a \Delta^{r}>0$ and a $k^{o}>0$ such that the dynamic system (9)-(10) has precisely two steady states $\left(k_{1}^{*}, q^{*}\right)$ and $\left(k_{2}^{*}, q^{*}\right)$, where $k_{2}^{*}>k_{1}^{*}$.

Lemma 5 Under assumption \& the investment choice problem of the young agents has a unique solution $x(q)$ for all $q>\underline{q}$ and no solution for $q \leq \underline{q}$, where $\underline{q} \in(0,1)$ is the unique solution of the equation $g(-q)=-1$. The function $x:(\underline{q}, \infty) \rightarrow \mathbf{R}$ is continuously differentiable, strictly increasing and satisfies $\lim _{x \rightarrow \infty} x(q)=\infty$. If assumption 5 holds as well, then there exists a unique $q^{*}$ such that $g\left(x\left(q^{*}\right)\right)=\gamma$ and we have $q^{*} \geq 1$.

Proof: As $g(0)=0, g^{\prime}(0)=1$ and $g^{\prime \prime}(x)<0$, we have $g(x) \leq x$ with strict inequality for $x \neq 0$. In particular we have $\lim _{x \rightarrow-\infty} g(x)=-\infty$. Then the equation $g(-q)=-1$ has precisely one solution $\underline{q}$, which must lie the interval $(0,1)$.

Now consider the problem of a young agent with savings $s>0$ of choosing his investment optimally, facing a price of capital of $q>0$. His problem is

$$
\max _{(x, k) \in \mathbf{R}^{2}}(1+g(x)) k \quad \text { s.t. } \quad(x+q) k \leq s \wedge k \geq 0 .
$$

Clearly this problem has no solution if $g(-q)>-1$, that is if $q<\underline{q}$. In this case the agent could set $x=-q$. Then the first constraint is satisfied for all $k \geq 0$ and the objective $(1+g(-q)) k$ can be made arbitrarily large.

So consider the case $g(-q) \leq-1$, that is $q \geq \underline{q}$. In this case the agent can achieve a positive value of the objective by setting $x=0$ and $k=\frac{s}{q}$. As choosing $x \leq-\underline{q}$ makes the objective non-positive and setting $k=0$ makes the objective zero, we only need to consider $x>-\underline{q} \geq-q$ and $k>0$. Among these choices, it is clear that $(x+q) k<s$ cannot be optimal. So if

$$
\frac{1+g(x)}{x+q}
$$

has a unique maximizer $x(q)$ in $(-\underline{q},+\infty)$, then $\left(x(q), \frac{s}{x(q)+q}\right)$ is the unique solution to the maximization problem of the agent. The derivative of this function with respect to $x$ is

$$
\frac{g^{\prime}(x)(x+q)-(1+g(x))}{(x+q)^{2}} .
$$

Consider the numerator

$$
D_{q}(x)=g^{\prime}(x)(x+q)-(1+g(x)) \text {. }
$$


We have

$$
D_{q}(-\underline{q})=g^{\prime}(-\underline{q})(q-\underline{q})
$$

and

$$
D_{q}^{\prime}(x)=g^{\prime \prime}(x)(x+q)<0
$$

for all $x \in(-\underline{q},+\infty)$. If $q=\underline{q}$, then $D_{q}(-\underline{q})=0$. In this case the agent would like to set $x$ arbitrarily close to $-\underline{q}$, so the problem does not have a solution. However, if $q>\underline{q}$, we have $D_{q}(-\underline{q})>0$.

Moreover, as $g$ is concave,

$$
D_{q}(x) \leq g^{\prime}(x) q-1
$$

So

$$
\lim _{x \rightarrow \infty} D_{q}(x) \leq-1
$$

Thus the equation $D_{q}(x)=0$ has a unique solution $x(q)$ which is the unique maximizer on $(-\underline{q},+\infty)$ of the expression in equation (26).

So now we have constructed the function $x:(\underline{q},+\infty) \rightarrow \mathbf{R}$, and it satisfies

$$
g^{\prime}(x(q))(q+x(q))=(1+g(x(q)))
$$

for all $q \in(\underline{q},+\infty)$. By the implicit function theorem, the function $x(q)$ is continuously differentiable and we have

$$
x^{\prime}(q)=\frac{-g^{\prime}(x(q))}{g^{\prime \prime}(x(q))(x(q)+q)}>0,
$$

so $x(q)$ is strictly increasing. Suppose $\lim _{q \rightarrow \infty} x(q)=\bar{x}<\infty$. As $g^{\prime}(\bar{x})>0$, taking limits of $(27)$ as $q \rightarrow \infty$ yields infinity for the left hand side but $1+g(\bar{x})<\infty$ for the right hand side. Thus it must be the case that $\lim _{q \rightarrow \infty} x(q)=\infty$.

By substituting $q=1$ into equation (27) we see that $x(1)=0$.

Finally consider the equation

$$
g(x(q))=\gamma
$$

We have

$$
g(x(1))=0
$$

and since $\lim _{q \rightarrow \infty} x(q)=\infty$ and $\lim _{x \rightarrow \infty} g(x)=\infty$ we have $\lim _{q \rightarrow \infty} g(x(q))=\infty$. Thus if $\gamma \geq 0$ there is a unique $q^{*}$ solving equation (28) and clearly $q^{*} \geq 1$.

Lemma 6 Let assumptions $1-5$ be satisfied. Then for all $q>\underline{q}$, the equation

$$
\tilde{s}(w(k), r)=(x(q)+q) k
$$


has a unique solution $\tilde{r}(k, q)$ for all $k \in(0, \bar{k}(q))$ where $\bar{k}(q)>0$ is the unique solution to the equation

$$
w(k)=(x(q)+q) k .
$$

The function $\tilde{r}(k, q)$ is continuously differentiable and satisfies $\lim _{k \uparrow \bar{k}(q)} \tilde{r}(k, q)=\infty$.

Proof: Let $q>\underline{q}$ and $k>0$. We begin by analyzing equation (30). Consider the function $E_{q}: \mathbf{R}_{+} \rightarrow \mathbf{R}$ where

$$
E_{q}(k)=w(k)-(x(q)+q) k .
$$

Then $\lim _{k \downarrow 0} E_{q}(0)=0$ and

$$
E_{q}^{\prime}(k)=w^{\prime}(k)-(x(q)+q)
$$

The assumption that $\lim _{k \downarrow 0} w^{\prime}(k)=+\infty$ ensures that $E_{q}(k)$ is strictly positive for sufficiently small $k$. As long as $w^{\prime}(k)$ is strictly positive, it is strictly decreasing. Taking into account the limits of $w^{\prime}(k)$, this means that the equation $E_{q}^{\prime}(k)=0$ has a unique solution $k_{\max }$ which is the global maximizer of $E_{q}$. Then we have $E_{q}\left(k_{\max }\right)>0$ and $E_{q}^{\prime}(k)<0$ for $k>k_{\max }$. Moreover, $\lim _{k \uparrow \infty} w^{\prime}(k)=0$ implies that $E_{q}(k)$ eventually turns negative. Hence there is a unique $\bar{k}(q) \in(0,+\infty)$ such that $E_{q}(\bar{k}(q))=0$. The function $\bar{k}:(\underline{q}, \infty) \rightarrow \mathbf{R}_{+}$is continuously differentiable by the implicit function theorem.

Now consider equation (29). The left hand side is increasing in $r$ and satisfies $\tilde{s}(w(k),-1)=$ 0 and $\lim _{r \rightarrow \infty} \tilde{s}(w(k), r)=w(k)$. So the equation has at most one solution $\tilde{r}(k, q)$, and this solution exists if and only if $k<\bar{k}(q)$. The function $\tilde{r}(k, q)$ is continuously differentiable by the implicit function theorem and

$$
\tilde{r}_{k}(k, q)=\frac{1-\left(\frac{\tilde{s}_{w}(w(k), \tilde{r}(k, q)) w(k)}{\tilde{s}(w, \tilde{r}(k, q))}\right) \cdot\left(\frac{w^{\prime}(k) k}{w(k)}\right)}{\frac{\tilde{s}_{r}(w(k), \tilde{r}(k, q)) k}{\tilde{s}(w(k), \tilde{r}(k, q))}}>0 .
$$

It is also easy to see that $\lim _{k \uparrow \bar{k}(q)} \tilde{r}(k, q)=+\infty$. Suppose $\lim _{k \uparrow \bar{k}(q)} \tilde{r}(k, q)=\bar{r}<\infty$, then taking limits of

$$
\tilde{s}(w(k), \tilde{r}(k, q))=(x(q)+q) k
$$

as $k \uparrow \bar{k}(q)$ yields

$$
\tilde{s}(w(\bar{k}(q)), \bar{r})=(x(q)+q) \bar{k}(q),
$$

which contradicts the fact that for finite $\bar{r}$ we have

$$
\tilde{s}(w(\bar{k}(q)), \bar{r})<w(\bar{k}(q))=(x(q)+q) \bar{k}(q) .
$$


Lemma 7 Let assumptions $1-5$ be satisfied. Then for all $q>\underline{q}$, the equation

$$
s(w(k), r)=(x(q)+q) k
$$

has a unique solution $r(k, q)$ for all $k \in(0, \bar{k}(q))$ and

$$
r(k, q)=\tilde{r}(k, q)-I\left(k \geq k_{0}\right) \Delta^{r}
$$

where the function $\bar{k}$ and $\tilde{r}$ are as in lemma 6 . The function $r(k, q)$ is continuously differentiable except at points $(q, k)$ with $k=k^{o}$, and $\lim _{k \uparrow \bar{k}(q)} r(k, q)=\infty$.

Proof: Suppose $q>\underline{q}$ and $k \in(0, \bar{k}(q))$. Then the equation

$$
\tilde{s}(w(k), r)=(x(q)+q) k
$$

has the unique solution $\tilde{r}(k, q)$. Suppose $k<k^{o}$, then $s(w(k), r)=\tilde{s}(w(k), r)$ for all $r \in$ $[-1, \infty)$ and consequently $r(k, q)=\tilde{r}(k, q)$ is the unique solution of equation (31).

If $k \geq k^{o}$ equation (31) can be written as

$$
\tilde{s}\left(w(k), r+\Delta^{r}\right)=(x(q)+q) k,
$$

which has the unique solution $r(k, q)=\tilde{r}(k, q)-\Delta^{r}$. The properties of the function $r(k, q)$ then follow from lemma 6 .

Proof of proposition 1: Given the results of the preceding lemmas, $\left(k^{*}, q^{*}\right)$ is a steady state if and only if $k^{*}$ satisfies the equation $m(k)=0$ where

$$
m(k)=\frac{\tilde{r}\left(k, q^{*}\right)-I\left(k \geq k_{0}\right) \cdot \Delta^{r}-G_{K}\left\langle x\left(q^{*}\right)\right\rangle}{1+G_{K}\left\langle x\left(q^{*}\right)\right\rangle}-f^{\prime}(k) .
$$

The function $m(k)$ is continuous and strictly increasing except for a downward jump at $k^{o}$. Hence the equation $m(k)=0$ has at most two solutions. We will choose $k^{o}$ and $\Delta^{r}$ so that there are precisely two solutions. Consider the function

$$
\tilde{m}(k)=\frac{\tilde{r}\left(k, q^{*}\right)-G_{K}\left\langle x\left(q^{*}\right)\right\rangle}{1+G_{K}\left\langle x\left(q^{*}\right)\right\rangle}-f^{\prime}(k) .
$$

It is continuous on $(0,+\infty)$ and has $\tilde{m}^{\prime}(k)>0$ for all $k \in(0,+\infty), \lim _{k \downarrow 0} m(k)=-\infty$ and $\lim _{k \uparrow \bar{k}\left(q^{*}\right)} m(k)=+\infty$. Thus there exists a unique $k_{1}^{*} \in\left(0, \bar{k}\left(q^{*}\right)\right)$ such that $\tilde{m}\left(k_{1}^{*}\right)=0$. Choosing $k^{o} \in\left(k_{1}^{*}, \bar{k}\left(q^{*}\right)\right)$, we also have $m\left(k_{1}^{*}\right)=0$.

Next consider the function

$$
\tilde{m}_{\Delta^{r}}(k)=\frac{\tilde{r}\left(k, q^{*}\right)-\Delta^{r}-G_{K}\left\langle x\left(q^{*}\right)\right\rangle}{1+G_{K}\left\langle x\left(q^{*}\right)\right\rangle}-f^{\prime}(k) .
$$

For each $\Delta^{r} \in$ there is a unique $k_{2}\left(\Delta^{r}\right)$ such that $\tilde{m}_{\Delta^{r}}\left(k_{2}\left(\Delta^{r}\right)\right)=0$. The function $k_{2}\left(\Delta^{r}\right)$ is strictly increasing and $\lim _{\Delta^{r} \rightarrow \infty} k_{2}\left(\Delta^{r}\right)=\bar{k}\left(q^{*}\right)$. Choosing $\Delta^{r}$ such that $k_{2}^{*}=k_{2}\left(\Delta^{r}\right)>k^{o}$, we have $m\left(k_{2}^{*}\right)=0$. 
Assumption 6 There exists $\bar{k} \in(0,+\infty)$ such that $f^{\prime}(k)>0$ for all $k<\bar{k}$ and $f^{\prime}(k)=0$ for all $k \geq \bar{k}$. Moreover $w(\bar{k})<\left(x\left(q^{*}\right)+q^{*}\right) \bar{k}$ where $q^{*}$ is as in lemma 5 .

Definition 1 1. A speculative path $\left\{k_{t}, q_{t}\right\}_{t=0}^{\infty}$ is an equilibrium path with origin $k_{0}<k^{o}$ that converges to the high valuation steady state $\left(k_{H}^{*}, q^{*}\right)$.

2. The price of capital at time $t$ along a speculative path has a bubble component if there exists $N$ such that $n \geq N$ implies $f^{\prime}\left(k_{t+n}\right)=0$.

3. The price of capital at time $t$ along a speculative path is a pure bubble if $f^{\prime}\left(k_{t+n}\right)=0$ for all $n \geq 1$.

Proposition 2 Under assumptions 1-6, there exists $a \Delta^{r}>0$ and a $k^{o}>0$ such that the dynamic system (9)-(10) has precisely two steady states $\left(k_{1}^{*}, q^{*}\right)$ and $\left(k_{2}^{*}, q^{*}\right)$, where $k_{1}^{*}<k^{o}<k_{2}^{*}$ and $k_{2}^{*}>\bar{k}$. Along the low cost-of-capital equilibrium path, the price of capital includes a bubble component and becomes a pure bubble for all $k \geq \bar{k}$.

Proof: The second part of assumption 6 implies $\bar{k}<\bar{k}\left(q^{*}\right)$ where $\bar{k}\left(q^{*}\right)$ is defined as in lemma 5.

From proposition 1 we can choose $k^{o}$ and $\Delta^{r}$ such that there are precisely two steady states $\left(k_{1}^{*}, q^{*}\right)$ and $\left(k_{2}^{*}, q^{*}\right)$ with $k_{1}^{*}<k^{o}<k_{2}^{*}$.

Recall that in the proof of that proposition we constructed $k_{2}^{*}$ by choosing $\Delta^{r}$ such that $k_{2}\left(\Delta^{r}\right)>k^{o}$. But as $\lim _{\Delta^{r} \rightarrow \infty} k_{2}\left(\Delta^{r}\right)=\bar{k}\left(q^{*}\right)$ and both $k^{o}<\bar{k}\left(q^{*}\right)$ and $\bar{k}<\bar{k}\left(q^{*}\right)$, we can also choose $\Delta^{r}$ such that $k_{2}\left(\Delta^{r}\right)>\max \left(k^{o}, \bar{k}\right)$.

As a speculative path $\left\{k_{t}, q_{t}\right\}_{t=0}^{\infty}$ converges to $\left(k_{2}^{*}, q^{*}\right)$ by definition, there exists $N$ such that $t \geq N$ implies that $k_{t} \geq \bar{k}$ and thus $f^{\prime}\left(k_{t}\right)=0$. Hence $q_{t}$ has a bubble component for all $t \geq 0$. As $k_{t+1} \geq k_{t}$ for all $t \geq 0$ along a speculative path, $k_{t} \geq \bar{k}$ implies that $q_{t}$ is a pure bubble.

\section{B Parametric Example Underlying Figure 3}

This appendix provides the functional forms and parameter values underlying the simulations presented in figure 3 . The following functional forms were used:

$$
\begin{aligned}
f(k) & =k^{\xi}, \\
g(x) & =x-\phi x^{2}, \\
\widetilde{s}(w, r) & =\sigma(r) w,
\end{aligned}
$$


Table A.1: parameters

\begin{tabular}{cc}
\hline \hline parameter & value \\
\hline$\xi$ & 0.05 \\
$\phi$ & 0.4 \\
$\beta$ & 0.76 \\
$\theta$ & 20 \\
$k^{o}$ & 0.157 \\
$\Delta^{r}$ & 0.054 \\
$\gamma$ & 0.25 \\
\hline
\end{tabular}

where

$$
\sigma(r)=\frac{\beta^{\theta}(1+r)^{\theta-1}}{1+\beta^{\theta}(1+r)^{\theta-1}} .
$$

With $\xi \in(0,1)$ the production function satisfies all the assumptions stated in the text. The functional form for $g$ yields the investment function

$$
x(q)=-q+\sqrt{q^{2}+\frac{q-1}{\phi}} .
$$

The domain of $x$ is $[\underline{q}, \infty)$ and its range is given by $\left[-\underline{q}, \frac{1}{2 \phi}\right)$ where

$$
\underline{q}=-\frac{1}{2 \phi}+\sqrt{\frac{1}{4 \phi^{2}}+\frac{1}{\phi}} .
$$

Note that the function $g$ satisfies $g^{\prime}(x)>0$ only for $x<\frac{1}{2 \phi}$, but as $x(q)<\frac{1}{2 \phi}$ we have $g^{\prime}(x(q))>0$ as well as $g^{\prime \prime}(x(q))<0$ for all $q \in[\underline{q}, \infty)$.

The functional form for $g$ also yields

$$
G_{K}\langle x\rangle=\phi x^{2}
$$

The saving function $\widetilde{s}$ is derived from a CES utility function with elasticity of substitution $\theta$ and discount factor $\beta$. It satisfies $\widetilde{s}_{w}>0$ and setting $\theta>1$ insures $\widetilde{s}_{r}>0$.

Using equation (12) we obtain the interest rate function

$$
r(k, q)=\left\{\begin{array}{cc}
\sigma^{-1}\left(\frac{(x(q)+q) k^{1-\xi}}{1-\xi}\right), & k<k^{o} \\
\sigma^{-1}\left(\frac{(x(q)+q) k^{1-\xi}}{1-\xi}\right)-\Delta^{r}, & k \geq k^{o} .
\end{array}\right.
$$

Clearly $r_{k}>0$ for $k<k^{o}$ as well as for $k>k^{o}$.

The parameter values used are given in table A.1. 


\section{Proof of Proposition 3}

Assumption 7 The production function $f$ satisfies assumption 1 and in addition $f^{\prime \prime}(k)<0$ for all $k \in \mathbf{R}_{+}$.

Proposition 3 Under assumptions 3-5 and 7 there exist $r^{+}>0, \Delta^{r o}>0$ and $z^{o}>0$ such that the dynamic system (9)-(10) has precisely two steady states $\left(k_{1}^{*}, q^{*}\right)$ and $\left(k_{2}^{*}, q^{*}\right)$, where $k_{2}^{*}>k_{1}^{*}$.

Proof: We begin by choosing $r^{+}, \Delta^{r o}$ and $z^{o}>0$ such that there are precisely two steady states with positive levels of $z$. Then we show that for these values of $r^{+}, \Delta^{r o}$ and $z^{o}>0$ there is no steady state with $z=0$. We set $\rho=0$ as this plays no qualitative role in the proposition.

From lemma 5 the function $x(q)$ is well defined and there is a unique $q^{*}$ such that $g\left(x\left(q^{*}\right)\right)=$ $\gamma$. Consider the function $E_{q^{*}}: \mathbf{R}_{+} \rightarrow \mathbf{R}$ with

$$
E_{q^{*}}(k)=\frac{1}{2} w(k)-\left(x\left(q^{*}\right)+q^{*}\right) k .
$$

As discussed in the proof of lemma 6 this function has a unique global maximizer $k_{\max }$ such that $E_{q^{*}}\left(k_{\max }\right)>0, E_{q^{*}}^{\prime}(k)>0$ for $k<k_{\max }$ and $E_{q^{*}}^{\prime}(k)<0$ for $k>k_{\max }$. So we can choose $z^{o}$ such that

$$
0<(1+\gamma) z^{o}<E_{q^{*}}\left(k_{\max }\right)
$$

and as $\lim _{k \rightarrow 0} E_{q^{*}}(k)=0$ and $\lim _{k \rightarrow \infty} E_{q^{*}}(k)=-\infty$ the equation $E_{q^{*}}(k)=(1+\gamma) z^{o}$ has precisely two solutions $0<\widetilde{k}^{l}\left(q^{*}\right)<\widetilde{k}^{u}\left(q^{*}\right)$. Also note that there is a unique $\bar{k}\left(q^{*}\right)$ such that $E_{q^{*}}\left(\bar{k}\left(q^{*}\right)\right)=0$.

Now if $z>0$ then

$$
r\left(k, q^{*}\right)=\left\{\begin{array}{cr}
r^{+}, & 0<k<\widetilde{k}^{l}\left(q^{*}\right) \text { or } \quad \widetilde{k}^{u}\left(q^{*}\right)<k<\bar{k}\left(q^{*}\right), \\
r^{+}-\Delta^{r o}, & \widetilde{k}^{l}\left(q^{*}\right) \leq k \leq \widetilde{k}^{u}\left(q^{*}\right),
\end{array}\right.
$$

where $\Delta^{r o}$ is still to be determined. The capital stock in a steady state with $z>0$ must satisfy the equation $m(k)=0$ where

$$
m(k)=\frac{r\left(k, q^{*}\right)-G_{K}\left\langle x\left(q^{*}\right)\right\rangle}{1+G_{K}\left\langle x\left(q^{*}\right)\right\rangle}-f^{\prime}(k) .
$$

The function $m(k)$ is strictly increasing and continuous except for a downward jump at $\widetilde{k}^{l}\left(q^{*}\right)$ and an upward jump at $\widetilde{k}^{u}\left(q^{*}\right)$. Hence the equation $m(k)=0$ has at most two solutions. We will now choose $r^{+}$and $\Delta^{r o}$ such that there will be precisely two solutions. 
Pick $k_{1}^{*} \in\left(0, \widetilde{k}^{l}\left(q^{*}\right)\right)$ and set

$$
r^{+}=\left(1+G_{K}\left\langle x\left(q^{*}\right)\right\rangle\right)\left(1+\frac{f^{\prime}\left(k_{1}^{*}\right)}{q^{*}}\right)-1>0 .
$$

Similarly pick $k_{2}^{*} \in\left(\widetilde{k}^{l}\left(q^{*}\right), \widetilde{k}^{u}\left(q^{*}\right)\right)$ and set

$$
\Delta^{r o}=1+r^{+}-\left(1+G_{K}\left\langle x\left(q^{*}\right)\right\rangle\right)\left(1+\frac{f^{\prime}\left(k_{2}^{*}\right)}{q^{*}}\right) .
$$

Then $k_{2}^{*}>k_{1}^{*}$ and both satisfy the equation $m(k)=0$. Choosing $k_{2}^{*}$ sufficiently close to $\widetilde{k}^{l}\left(q^{*}\right)$ insures that $\Delta^{r o}<r^{+}$.

Now suppose there is a steady state with $z=0$. Then the capital stock in this steady state must be equal to $\bar{k}\left(q^{*}\right)>k_{1}^{*}$, which implies a steady state interest rate

$$
r=\left(1+G_{K}\left\langle x\left(q^{*}\right)\right\rangle\right)\left(1+\frac{f^{\prime}\left(\bar{k}\left(q^{*}\right)\right)}{q^{*}}\right)-1<r^{+},
$$

but at this interest rate agents would want to invest in $z$, so $z=0$ is inconsistent with equilibrium.

\section{Proof of Proposition 4}

Assumption 8 The interest rate $r^{+}-\Delta^{r o}$ is strictly less than the rate of technological progress $\gamma$.

Proposition 4 Let $g_{t}=\bar{g}+\alpha \bar{\tau}\left(w_{t}-w^{*}\right)$. Suppose that the economy satisfies assumption 8. Also suppose that for $\alpha=0$ it has two steady states $\left(k_{1}^{*}, q^{*}, d_{1}^{*}\right)$ and $\left(k_{2}^{*}, q^{*}, d_{2}^{*}\right)$ with $k_{2}^{*}>k_{1}^{*}$. Then there exists $\alpha^{m}>0$ such that for any $\alpha \geq \alpha^{m}$ the high-valuation equilibrium disappears.

Proof: Let $\alpha \geq 0$ be given and suppose the high-valuation equilibrium exists for this $\alpha$. The two steady state capital stocks are given by

$$
\begin{aligned}
& k_{1}^{*}=\left(f^{\prime}\right)^{-1}\left(\frac{r^{+}-G_{K}\left\langle x\left(q^{*}\right)\right\rangle}{1+G_{K}\left\langle x\left(q^{*}\right)\right\rangle}\right), \\
& k_{2}^{*}=\left(f^{\prime}\right)^{-1}\left(\frac{r^{+}-\Delta^{r o}-G_{K}\left\langle x\left(q^{*}\right)\right\rangle}{1+G_{K}\left\langle x\left(q^{*}\right)\right\rangle}\right) .
\end{aligned}
$$

Note that $k_{2}^{*}$ does not depend on $\alpha$ as there are only two levels for the interest rate in this economy.

Now the interest rate in the high-valuation steady state must be $r^{+}-\Delta^{r o}$. This requires that the implied steady state value of $z$ exceeds $z^{o}$. This yields the condition

$$
\frac{1}{2}(1-\bar{\tau}) w\left(k_{2}^{*}\right)+\left(\bar{\tau} w\left(k_{2}^{*}\right)-g_{2}^{*}\right)-\left(1+r_{2}^{*}\right) d_{2}^{*}-\left(x\left(q^{*}\right)+q^{*}\right) k_{2}^{*}>(1+\gamma) z^{o}
$$


where $g_{2}^{*}=\bar{g}+\alpha \bar{\tau}\left(w\left(k_{2}^{*}\right)-w\left(k_{1}^{*}\right)\right)$ is government spending and $r_{2}^{*}=r^{+}-\Delta^{r o}$ is the interest rate in the high-valuation steady state. Using equation (23), we obtain

$$
d_{2}^{*}=-\frac{\bar{\tau} w\left(k_{2}^{*}\right)-g_{2}^{*}}{\gamma-r_{2}^{*}} .
$$

Using the fact that $\bar{g}=\bar{\tau} w\left(k_{1}^{*}\right)$, we have

$$
\bar{\tau} w\left(k_{2}^{*}\right)-g_{2}^{*}=(1-\alpha) \bar{\tau}\left(w\left(k_{2}^{*}\right)-w\left(k_{1}^{*}\right)\right) .
$$

Then we can rewrite condition (36) as

$$
\frac{1}{2}(1-\bar{\tau}) w\left(k_{2}^{*}\right)+\frac{1+\gamma}{\gamma-r_{2}^{*}}(1-\alpha) \bar{\tau}\left(w\left(k_{2}^{*}\right)-w\left(k_{1}^{*}\right)\right)-\left(x\left(q^{*}\right)+q^{*}\right) k_{2}^{*}>(1+\gamma) z^{o} .
$$

By assumption this condition is satisfied for $\alpha=0$. But as the left hand side is linear in $\alpha$ with a negative coefficient, there exists $\alpha^{m}>0$ such for all $\alpha \geq \alpha^{m}$ the condition is violated and the high-valuation steady state does not exist. 


\section{References}

[1] Abel, A.B., N.G. Mankiw, L. H. Summers and R. J. Zeckhauser (1989): "Assessing Dynamic Efficiency: Theory and Evidence," Review of Economic Studies, 56, 1-20.

[2] Carroll, Christopher D., and David N. Weil (1994): "Saving and Growth: A Reinterpretation," Carnegie-Rochester Conference Series on Public policy, 40, 133-192.

[3] Cecchetti, Stephen G., Hans Genberg, John Lipsky and Sushil B. Wadhwani (2000): Asset Prices and Central Bank Policy, Geneva Reports on the World Economy 2, London: Center for Economic Policy Research.

[4] Chirinko, R.S., and H. Schaller (2001), "Business Fixed Investment and "Bubbles": The Japanese Case," American Economic Review, June, 663-680.

[5] Cozzi, G. (1998), "Culture as a Bubble," Journal of Political Economy, vol. 106(2), 376-394.

[6] Diamond, Peter (1965): "National Debt in a Neoclassical Growth Model," American Economic Review, 55, 1126-1150.

[7] Gavin, M., R. Hausmann, E. Talvi (1997), "Saving Behavior in Latin America: Overview and Policy Issues," IADB Wp \#346, May.

[8] Greenwood, Jeremy, and Boyan Jovanovic (1999): "The Information-Technology Revolution and the Stock Market," American Economic Review (Papers and Proceedings), $89(2), 116-122$.

[9] Grossman, G., and N. Yanagawa (1993): "Asset Bubbles and Endogenous Growth," Journal of Monetary Economics, 31, 3-19.

[10] Hobijn, Bart, and Boyan Jovanovic (2001): "The Information-Technology Revolution and the Stock Market: Evidence," American Economic Review, 91(5), 1203-1220.

[11] International Monetary Fund (2000): World Economic Outlook - Asset Prices and the Business Cycle, Washington: International Monetary Fund.

[12] Kindleberger, Charles P., (1989): Manias, Panics, and Crashes, (revised edition) Basic Books Inc., Harper Collins, USA.

[13] King, I., and D. Ferguson (1993): "Dynamic Inefficiency, Endogenous Growth and Ponzi Games," Journal of Monetary Economics, 79-104. 
[14] Olivier, Jacques (2000): "Growth-Enhancing Bubbles," International Economic Review, 41(1), 133-151.

[15] Rappoport, P. and E.N. White (1993): "Was there a Bubble in the 1929 Stock Market?" The Journal of Economic History 53-3, September, 549-574.

[16] Saint-Paul, Gilles (1992): "Fiscal Policy in an Endogenous Growth Model," European Economic Review, 36, 763-781.

[17] Shiller, Robert J. (2000): Irrational Exuberance, Princeton: Princeton University Press.

[18] Tirole, Jean (1985): "Asset Bubbles and Overlapping Generations," Econometrica, 53(6), 1499-1528.

[19] Ventura, Jaume (2001): "A Portfolio View of the U.S. Current Account Deficit," Brookings Papers on Economic Activity,1, 241-253.

[20] Weil, Philippe (1990): "On the Possibility of Price Decreasing Bubbles," Econometrica, $58(6), 1467-1474$.

[21] Woodford, Michael (1991): "Public Debt as Private Liquidity," American Economic Review, 80(2), 382-388. 